\title{
Liquefied Natural Gas in Mobile Applications-Opportunities and Challenges
}

\author{
Tomasz Banaszkiewicz $^{1}$ (), Maciej Chorowski ${ }^{1, *}$, Wojciech Gizicki $^{1}$ (), Artur Jedrusyna ${ }^{1}$, \\ Jakub Kielar ${ }^{1}$, Ziemowit Malecha ${ }^{1, *}$ (1), Agnieszka Piotrowska ${ }^{1}$, Jaroslaw Polinski ${ }^{1}$ (D), \\ Zbigniew Rogala $^{1}$ (D), Korneliusz Sierpowski ${ }^{1}$ (D), Janusz Skrzypacz ${ }^{1}$, Michal Stanclik $^{1}{ }^{\circledR}$, \\ Krzysztof Tomczuk ${ }^{1}$ and Piotr Dowżenko ${ }^{2}$ \\ 1 Department of Cryogenics and Aerospace Engineering, Wroclaw University of Science and Technology, \\ 50-370 Wrocław, Poland; tomasz.banaszkiewicz@pwr.edu.pl (T.B.); wojciech.gizicki@pwr.edu.pl (W.G.); \\ artur.jedrusyna@pwr.edu.pl (A.J.); jakub.kielar@pwr.edu.pl (J.K.); agnieszka.piotrowska@pwr.edu.pl (A.P.); \\ jaroslaw.polinski@pwr.edu.pl (J.P.); zbigniew.rogala@pwr.edu.pl (Z.R.); \\ korneliusz.sierpowski@pwr.edu.pl (K.S.); janusz.skrzypac@pwr.edu.pl (J.S.); \\ michal.stanclik@pwr.edu.pl (M.S.); Krzysztof.Tomczuk@pwr.edu.pl (K.T.) \\ 2 Remontowa LNG Systems, 84-230 Rumia, Poland; p.dowzenko@rls.rh.pl \\ * Correspondence: maciej.chorowski@pwr.edu.pl (M.C.); ziemowit.malecha@pwr.edu.pl (Z.M.)
}

Received: 15 July 2020; Accepted: 23 October 2020; Published: 30 October 2020

\begin{abstract}
Liquefied natural gas (LNG) is one of the most influential fuels of the 21st century, especially in terms of the global economy. The demand for LNG is forecasted to reach 400 million tonnes by 2020, increasing up to 500 million tonnes in 2030. Due to its high mass and volumetric energy density, LNG is the perfect fuel for long-distance transport, as well as for use in mobile applications. It is also characterized by low levels of emissions, which is why it has been officially approved for use as a marine fuel in Emission Control Areas (ECAs) where stricter controls have been established to minimize the airborne emissions produced by ships. LNG is also an emerging fuel in heavy road and rail transport. As a cryogenic fuel that is characterized by a boiling temperature of about $120 \mathrm{~K}\left(-153{ }^{\circ} \mathrm{C}\right)$, LNG requires the special construction of cryogenic mobile installations to fulfill conflicting requirements, such as a robust mechanical construction and a low number of heat leaks to colder parts of the system under high safety standards. This paper provides a profound review of LNG applications in waterborne and land transport. Exemplary constructions of LNG engine supply systems are presented and discussed from the mechanical and thermodynamic points of view. Physical exergy recovery during LNG regasification is analyzed, and different methods of the process are both analytically and experimentally compared. The issues that surround two-phase flows and phase change processes in LNG regasification and recondensation are addressed, and technical solutions for boil-off gas recondensation are proposed. The paper also looks at the problems surrounding LNG installation data acquisition and control systems, concluding with a discussion of the impact of LNG technologies on future trends in low-emission transport.
\end{abstract}

Keywords: liquefied natural gas; LNG fuel system; ecological transportation; land and marine transportation

\section{Introduction}

Liquefied natural gas (LNG) is natural gas cooled to approximately $111-120 \mathrm{~K}$ and converted to liquid for ease and safety in transport. LNG is approximately 600 times more dense than its gaseous form, enabling easier transportation and storage when pipeline transport is not feasible. Therefore, transportation of LNG across distances exceeding $1100 \mathrm{~km}$ offshore and $4000 \mathrm{~km}$ onshore is economically justified. 
Methane, which is the primary constituent of natural gas, was first liquefied by Karol Olszewski and Zygmunt Wroblewski in Krakow in 1886 [1,2]. The first large-scale liquefaction of natural gas in the U.S. took place in 1918 aiming to extract helium [3]. Twenty-two years later, in 1940 in Cleveland, USA, the first full-scale LNG commercial plant worldwide was commissioned. The plant was operated successfully for three years until rupture of cylindrical LNG tank in 20 October 1944. Tons of LNG was spilled over the plant and the surrounding neighborhoods. Consequently, the liquid evaporated and caught fire causing 130 fatalities [4-6].

This event suspended implementation of LNG facilities for over a decade. The next 15 years of research in terms of cryogenic construction and insulation materials finally led to revival of the LNG industry. Finally, in 1959 a U.S. World War II Liberty ship was converted to carry LNG and made a delivery from the USA to Great Britain.

The U.S. LNG industry restarted in 1965 with a series of new domestic plants. Plant construction continued through the 1970s. These plants were not only used for "peak-shaving", as in Cleveland, but also as a base-load of supplies for places that never had any natural gas before. A number of import facilities were built on the east coast, in anticipation of the need to import energy via LNG. However, by the mid-2000s, technological innovations, such as horizontal drilling, helped American natural gas producers unlock previously unreachable natural gas deposits, kicking off a "shale revolution" that has allowed the USA to become the world's top producer of oil and natural gas. Consequently, many countries (e.g., Poland) have based their energy safety on the mass import of LNG.

A typical LNG value chain is composed of gas production, liquefaction, shipping, regasification and pipeline delivery. LNG regasification is usually performed in close vicinity to import terminals using heat coming from a partial gas combustion (about $2 \%$ of the LNG to be liquefied), from the heat capacity of sea water or from atmospheric air. Regasification and pipeline delivery do not make use of two basic advantages of LNG—relatively high volumetric energy density (22.2 MJ/L) and physical exergy of the cold gas (1083 kJ/kg at 1 bar pressure). These two advantages make LNG a suitable fuel in mobile applications in waterborne and land transport.

Due to the constant tightening of greenhouse gas emissions standards and other environmentally harmful compounds such as sulfur oxides in the road transport sector, changes are also necessary, changes that adapt new but also used ships and vehicles to new standards. LNG installations used in waterborne and land transport have sizes varying by an order of magnitude ranging from the largest used in ship and rail transport to the smallest in small delivery vehicles. As of June 2020, there are about 200 LNG-powered vessels (excluding LNG carriers) and a similar number of confirmed orders for new vessels, while the consumption of LNG as maritime fuel is expected to grow five times from 2018 to 2022, due to larger vessels using it for propulsion [7].

The future number of LNG fueled ships, constructed or retrofitted, can be estimated as at least several dozens per year, and several hundreds or even thousands after 2030. According to the International Marine Organization (IMO) goals, the total GHG emissions will have to be reduced by at least $50 \%$ in 2050 compared to the 2008 emissions. It makes LNG the only low-emission, mature fuel for the forthcoming decade and definitely an intermediate fuel before a full conversion to zero-emission requirements after 2030. Most probably, complete zero emissions will be achieved with hydrogen and/or ammonia. LNG, being a cryogenic fuel, also plays an important role in technological adaptation of ships, vehicles and necessary infrastructure to cope with low-temperature and pressurized fuel requirements. In this sense it is an intermediate technology between conventional fuels like gasoline, diesel , LPG and liquid hydrogen.

The fact that LNG as a fuel will have a large share in road transport in the near future is evidenced by two closely related things: the first being the global trend of increasing demand for LNG in transport, as evidenced by data from previous years and the forecasts of the largest world exporters such as Russia, US and Shell [8-10].

The second direct indicator is the very dynamic increase in the number of LNG-powered vehicles. In China, over the period 2012-2018, this increase was almost 8 times from 50,000 to almost 400,000 [11]. 
In Europe, almost 5000 LNG-powered vehicles were registered at the end of 2018. By 2025, according to various forecasts, the increase may be from 10 to even 100 times $[12,13]$.

A vast use of LNG in mobile applications requires reliable and safe technical designs of the gas tanks, phase-change heat exchangers, instrumentation control systems and auxiliaries. The designs, components and whole LNG systems must meet the stringent requirements of certification bodies, such as DNV-GL (an international accredited registrar and classification society located in Hovik, Norway) for ships. Economy of LNG use in mobile applications can be significantly improved by its physical exergy recuperation (e.g., by direct cooling or a conversion to electrical power).

The authors have been involved in collaboration with a novel maritime industry for more than decade. The first European LNG supply system, aimed at the passenger ferry application, has been designed at Wrocław University of Science and Technology and produced by Remontowa LNG Systems Ltd, Rumia, Poland. The paper addresses the problems directly related the authors' LNG systems research and design experience. A profound literature review is presented to formulate the current state of LNG mobile applications and to describe the authors' work in a wider context.

The aim of the article is to review the technologies and technological challenges related to the use of LNG as fuel to power mobile transport units. The review includes a complete LNG process chain: LNG storage and storage safety systems, LNG regasification process and exergy recovery, recondesation of boiled-off LNG and auxiliary measurement systems. The discussed exergy recovery systems include ANG technology and thermoelectric generators (TEG). The ANG technology allows for a storage of natural gas at temperatures of $300 \mathrm{~K}$. It has potential to serve as an emergency tank, being loaded at a temperature of LNG and acting as a thermal compressor. It is an original approach and hard to find in scientific literature. The TEG technology is well known but mostly exploited in temperatures above $300 \mathrm{~K}$. There is very limited research related to the TEG usage at low temperatures, especially for the exergy recovery during LNG regasification.

In recent years a number of review papers related to LNG feasibility for powering of vehicles and vessels has been published. Most of them consider the economical or environmental aspects. The present review paper is focused on technological aspects of LNG handling and processing. The presented literature review was made according to the PRISMA P protocol. Google Scholar was searched over the period of the last five years (2015-2020) for review articles published over these years. The query "Liquefied Natural Gas in mobile applications review" showed 17 review articles. Subsequently, the search was narrowed specifically to "cold exergy" and "LNG exergy recovery". The outcome showed three and zero records, respectively. The review papers with the "cold exergy" phrase are listed below.

- Key Issues and Challenges on the Liquefied Natural Gas Value Chain: A Review from the Process Systems Engineering Point of View [14]

- Cold utilization systems of LNG: A review [15]

- Economic Process Selection of Liquefied Natural Gas Regasification: Power Generation and Energy Storage Applications [16]

The above-mentioned articles briefly discussed LNG processing technologies in mobile applications, and none of them considered the aspects related to storage of LNG, exergy recovery during LNG regasification, the LNG boil-off problem and auxiliary measurement systems as a whole.

The above motivated and substantiated the current extensive review article on LNG technology for mobile applications. One of the main advantages of this paper is a robust presentation of a complete LNG process chain needed to power a mobile system. The content of the article is largely the result of the authors' own research. The present review paper can be used as a source of comprehensive information for scientists, engineers and strategists to plan future research and development in the field of LNG use in mobile applications. 


\section{LNG in Waterborne Transport}

The use of natural gas as a maritime fuel is possible thanks to the development of dual-fuel engines. There are two types of dual-fuel engines: Otto cycle and Diesel cycle. The main difference between them is that Otto cycle engines require gas pressure at 5-6 bar while Diesel cycle engines require gas pressure at 250-300 bar [17].

The purpose of the gas fuel system (a simplified scheme of this system is presented in Figure 1) is to store and also to generate the required mass stream, pressure and temperature of the fuel that is being transferred to the engines. The gas is stored in the cryogenic vessel in the liquid phase (LNG), which can have a temperature as low as $111 \mathrm{~K}\left(-162^{\circ} \mathrm{C}\right)$. Before the gas is transferred to the engines, the LNG needs to be re-gasified and warmed to room temperature in the dedicated heat exchanger-vaporizer (VAP). Usually, the heating medium for the vaporizer is a water-glycol (WG) brine used to cool down the engines. The desired gas pressure can be achieved with the use of a gas compressor located downstream in the vaporizer, or with the use of a LNG pump immersed in the storage tank [17]. If the LNG tank is designed to be a pressure vessel, then it is possible to generate gas pressure inside the tank with the help of a pressure built unit (PBU)—an additional heat exchanger for the evaporation of a small portion of the LNG. The level of pressure generated in these tanks is sufficient to supply the Otto cycle engine, while for the Diesel cycle engines the gas needs extra compressing [17]. However, initial gas compression in the pressure tanks can reduce the required number of compression stages in the compression device. More details regarding the scheme of the possible maritime fuel gas system are discussed in [18].

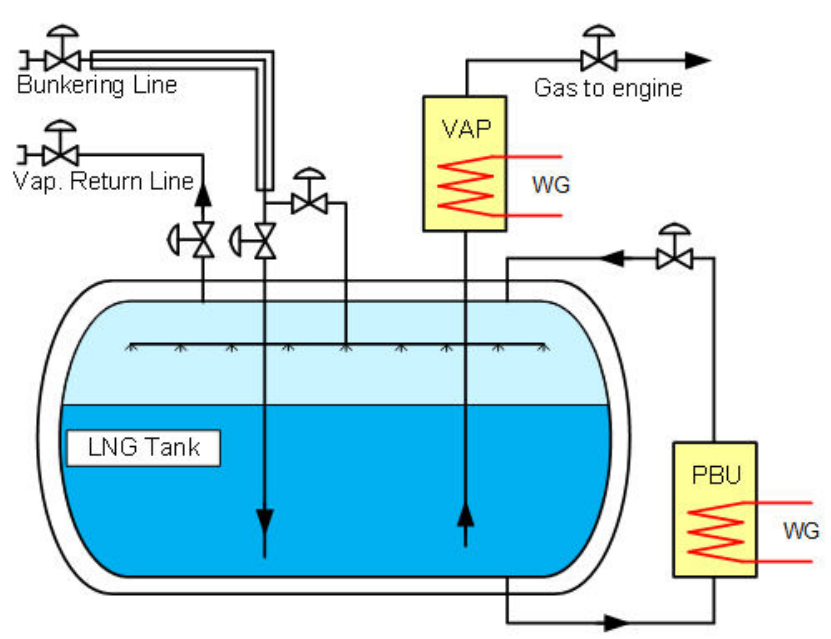

Figure 1. Simplified fuel gas flow scheme with a C-type tank (pressure vessel), liquefied natural gas (LNG) evaporator (heat exchanger-vaporizer; VAP) and thermal compressor (pressure built unit; PBU).

LNG for a fuel gas system can be stored in membrane tanks, with a design identical to LNG cargo tanks. Another option is to keep it in self-supporting, independent tanks that are not a part of the ship's hull structure. According to the IMO, IGC codes [19,20], there are three types of independent tanks: A, B and C. The shape of A and B-type tanks is accommodated to the shape of the hull, so it takes full advantage of the hull's volume. The Maximum Allowable Working Pressure (MAWP) of the tanks is limited to 0.7 bar gauge. Therefore, gas systems with this type of tank will always require compression devices for gas fuel preparation. The only difference between the A and B-type tanks is in their strength calculation methodology: A-type tanks require only the classical ship-structural analysis procedures while B-type tanks are calculated with the use of sophisticated models and methods to determine stress levels, fatigue life and crack propagation characteristics. As a result of this difference, A-type tanks require a full secondary barrier that is capable of containing all of the LNG stored in the tank in case of tank failure, while B-type tanks only require a partial secondary barrier. Due to a specific 
technology of the A- and B-type tanks fabrication, production of low-volume tanks is not economically justified. Therefore, the volumes of A- and B-type fuel tanks reach thousands of cubic meters and are mostly applied to deep sea and oceangoing vessels only. A $5000 \mathrm{~m}^{3} \mathrm{LNG}$ tank is sufficient to supply a $20 \mathrm{MW}$ (middle scale) output power vessel for about one month.

C-type tanks are pressurized tanks with MAWP limited by the IMO regulations to 10 bar, and they do not require a secondary barrier. Usually, these tanks are produced with a cylindrical or bilobe shape, so they take up much less of the hull volume than in the case of the membrane or for the independent A- or B-type tanks. In addition, the mass-to-volume ratio of the C-type is high; thus, the production costs of such tanks are much higher than they would be for the other types of tanks. C-type tanks can be produced in a variety of sizes, and their volumes range between a few tens of cubic meters for coastal vessels and low-range ferries, to a few hundred cubic meters for deep sea and oceangoing vessels.

Another aspect to consider for the LNG tanks is the length of time that the fuel can be held inside the tank prior to intake by the ship's engines. IMO regulations $[19,20]$ require that fuel pressure be kept below the set pressure of the tank pressure relief valves for a period of 15 days. This requirement can be fulfilled by the boil-off gas (BOG) pressure accumulation inside the tank or with the help of some additional equipment that can reliquefy the vapors, sub-cool the liquid or oxidize the fuel vapor. Due to the high MAWP and the possibility to apply highly effective vacuum-based thermal insulation, C-type tanks can fulfill the holding time requirements without the use of an extra BOG handling system. This is one of the reasons that C-type tanks are widely used in ship gas systems, despite drawbacks related to poor utilization of the hull volume and relatively high production costs.

Due to the low cryogenic temperature of LNG and the specific mechanical loads that result from offshore operation conditions, the fuel gas system design faces a number of challenges. The mechanical design of system components, including tanks or pipelines, is based on the standards and rules provided by classification societies such as DNV-GL, ABS and Lloyd's Register. Nevertheless, these standards are based on IMO IGC and IGF codes $[19,20]$. These documents define the requirements and technical problems that must be fulfilled and solved by designers.

The design process has to encompass all possible exploitation cases while also taking into account the 20-year operation time of the ship, static (internal and external pressure, vessel and cargo weight, etc.) and dynamic (accelerations due to the ship's motion, sloshing, etc.) mechanical loads as well as the thermal loads related to very low temperatures of LNG [21]. According to [21,22], the dynamic loads can be determined as accelerations in three directions, by taking rotation into account as presented in Figure 2.

$$
\begin{array}{r}
a_{z}= \pm a_{0} \sqrt{1+\left(5.3-\frac{45}{L}\right)^{2}\left(\frac{X}{L}+0.05\right)^{2}\left(\frac{0.6}{C_{B}}\right)^{\frac{2}{3}}} \\
a_{y}= \pm a_{0} \sqrt{0.6+2.5\left(\frac{X}{L}+0.05\right)^{2}+x\left(1+0.6 \frac{x z}{B}\right)^{2}} \\
a_{x}= \pm a_{0} \sqrt{0.06+A^{2}-0.25 A} \\
a_{t}=\sqrt{\left(a_{x}{ }^{2}+a_{y}^{2}+a_{z}^{2}\right)}
\end{array}
$$

where $\left(a_{z}, a_{y}, a_{x}, a_{t}\right)$ is the vertical, traverse, longitudinal and total acceleration, respectively, $L$ is the length between perpendiculars $m, \mathrm{X}$ is the distance from amidships to the tank's center of gravity, $\mathrm{C}_{\mathrm{B}}$ is the block coefficient, $x$ is the calculation factor of the metacentic height, $\mathrm{z}$ is the distance from water line to the tank's center of gravity, $\mathrm{A}$ is the calculation factor of relative accelerations and $\mathrm{B}$ is the breadth of vessel. 


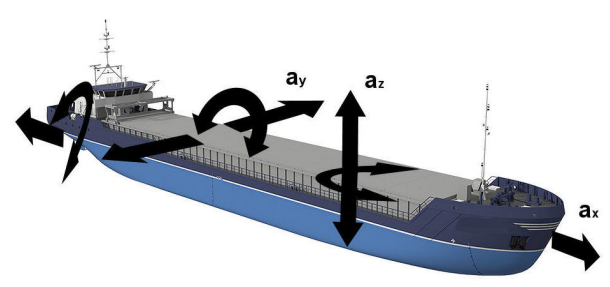

Figure 2. Accelerations acting on the ship due to movement, see Equation (1).

The acceleration values depend on the ship's design and operating parameters. For example, when a ship has a length of $\mathrm{L}=189 \mathrm{~m}$ and a service speed of $18 \mathrm{kn}$, the accelerations have the following values: $\mathrm{a}_{\mathrm{x}}=0.35 \mathrm{~g}, \mathrm{a}_{\mathrm{y}}=0.69 \mathrm{~g}, \mathrm{a}_{\mathrm{z}}=0.57 \mathrm{~g}$. The result of the dynamic loads is a cyclic (fatigue) loading of tank supports and increased internal pressure by a dynamic term that can be calculated based on the acceleration of the ellipsoid and using the method of the dynamic pressure determination [19]. Details about the fatigue calculations of the tank elements can be found in [23]. In addition, the classification society regulations may require a ship, thus its gas system, to be resistant to $2 \mathrm{~g}$ collision acceleration in transverse and longitudinal directions.

The possible structure of the C-type independent tank for use as an LNG fuel tank, designed by the authors, is presented in Figure 3. The process (cryogenic) tank is located inside the vacuum jacket (outer jacket) that provides appropriate thermal isolation. Typically, the vacuum space is filled with perlite powder characterized by low thermal conductivity and high fire-resistance. The $20-25 \mathrm{~cm}$ thickness of the vacuum-powder thermal isolation, together with the thermo-mechanically optimized design of the cryogenic tank's mechanical supports, makes it possible to apply the gas pressure accumulation method inside the tank. This fulfills the requirements regarding holding time and also protects the external tank surface against icing. Instead of powders, the vacuum space can also be filled with multilayer insulation that is installed on the cryogenic tank surface. In comparison with perlite powder, multilayer vacuum insulation provides heat loads to the cryogenic vessel that are one order of magnitude lower [24]. However, the cost of the insulation material is relatively high, its proper insulation properties require vacuum levels that are ten times greater and its effectiveness is very sensitive to vacuum degradation as well as to the installation process.

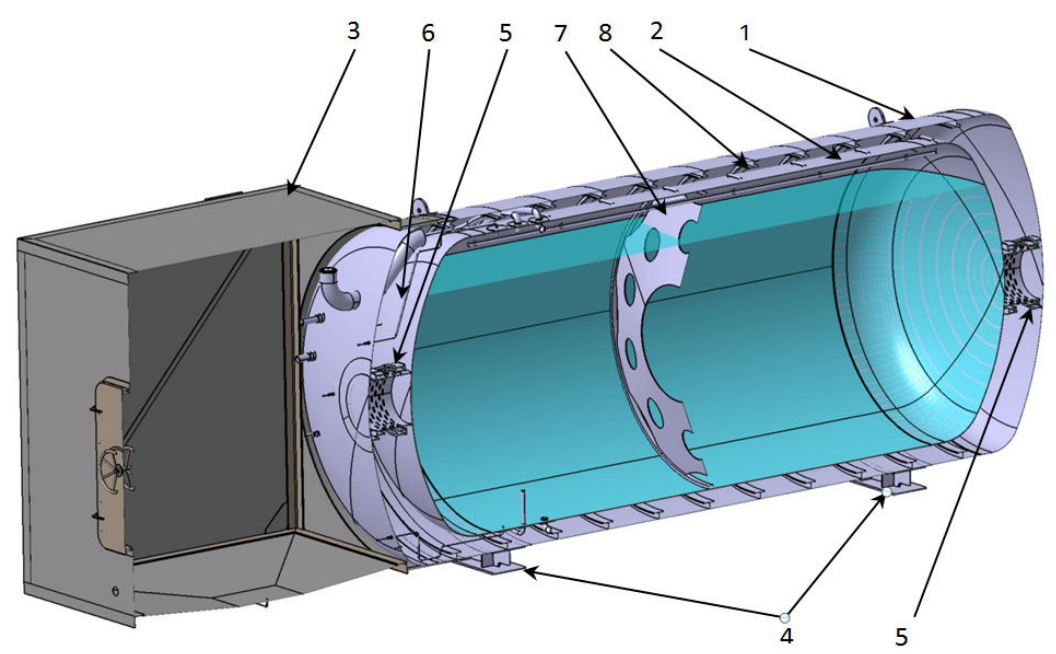

Figure 3. The main elements of the gas fuel system tank for LNG: 1—outer jacket; 2-process tank (inner tank); 3-tank connection space (TCS); 4-external supports; 5-internal supports; 6-pipes; 7—sloshing plate; 8-ribs. Design developed by the authors.

An alternative solution for thermal insulation is polyurethane (PUR), which can be applied by spraying a $25-30 \mathrm{~cm}$ thick foam layer on the cryogenic vessel surface. The external surface of the PUR 
foam is protected against moisture penetration by the epoxy resin coating or a stainless steel shell. As the foam's external protective layer is not designed to carry extensive mechanical loads, the cost of PUR-insulated tanks would be $40 \%$ lower than that of the vacuum-insulated tanks [25]. On the other hand, heat transfer through the PUR insulation is ten times higher than it would be for the vacuum perlite insulation. This means that a method other than gas pressure accumulation inside the cryogenic tank for BOG management would need to be applied, which can increase the total cost of the fuel gas system.

In the case of the vacuum-insulated tanks, there are two types of support: internal support, which carries the process tank inside the outer jacket, and external support, which carries the whole tank structure to the ship's deck. The process tank and the tank connection space (TCS) are connected by internal pipes. There are additional tank elements such as reinforcement plates, reinforcement rings, sloshing plates, etc.

The design of the internal piping and process tank supports requires thermo-mechanical optimization, as their cross-section has to be large enough to carry significant loads (static and dynamic) yet still be as small as possible in order to limit heat transfer to the process tank. The design of the internal supports can be based on elastomers or composite materials. Some examples of these types of structures can be found in [26], where the internal supports separate the process tank and the outer jacket.

The issues that may arise from using an elastomer or composite materials for internal supports are related to their relatively low mechanical strength and unverified long fatigue life (for areas that cannot be inspected, the fatigue life must be 10 times higher than that of the standard ship's elements). Thus, obtaining the proper materials certificate, which is issued by the classification society for the application of internal supports, can be problematic. Therefore, another approach is to use supports that are made of stainless steel, i.e., a material that provides good mechanical strength and which also has an acceptable and proven fatigue life. The main disadvantage of using stainless steel is it has thermal conductivity 10-20 times higher than that of an elastomer or for composite materials. In order to limit the heat transfer, the stainless steel supports have to be designed with a minimal cross-section area and maximal length for heat conduction. Some examples of structures like this are shown in Figures 4 and 5 (based on the author's work).

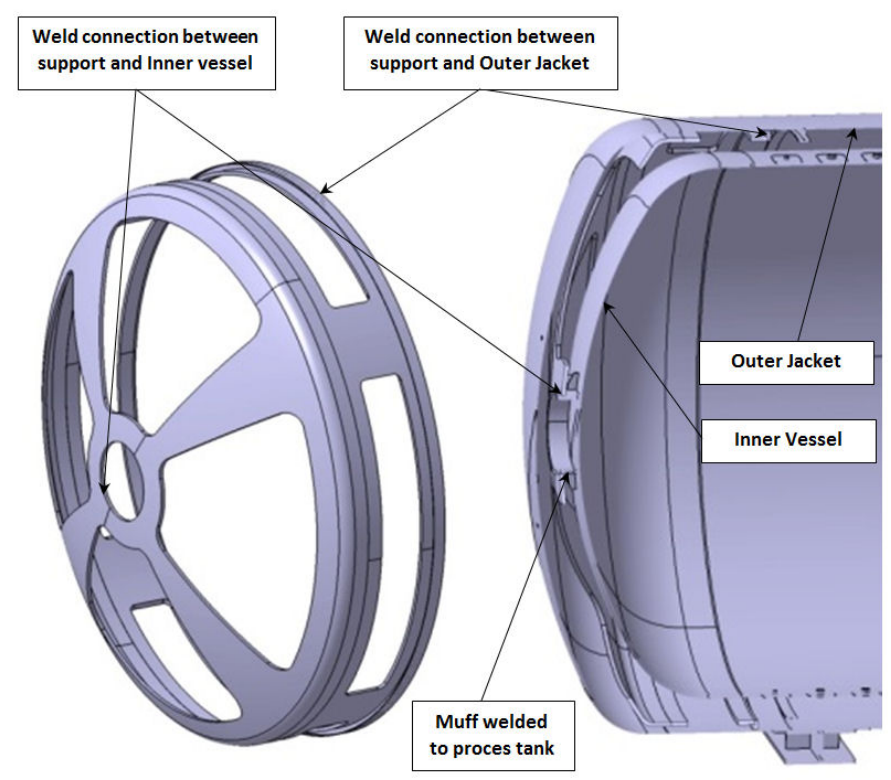

Figure 4. Example of internal supports with marked locations for welded connections to the outer jacket and process tank. Design developed by the authors. 


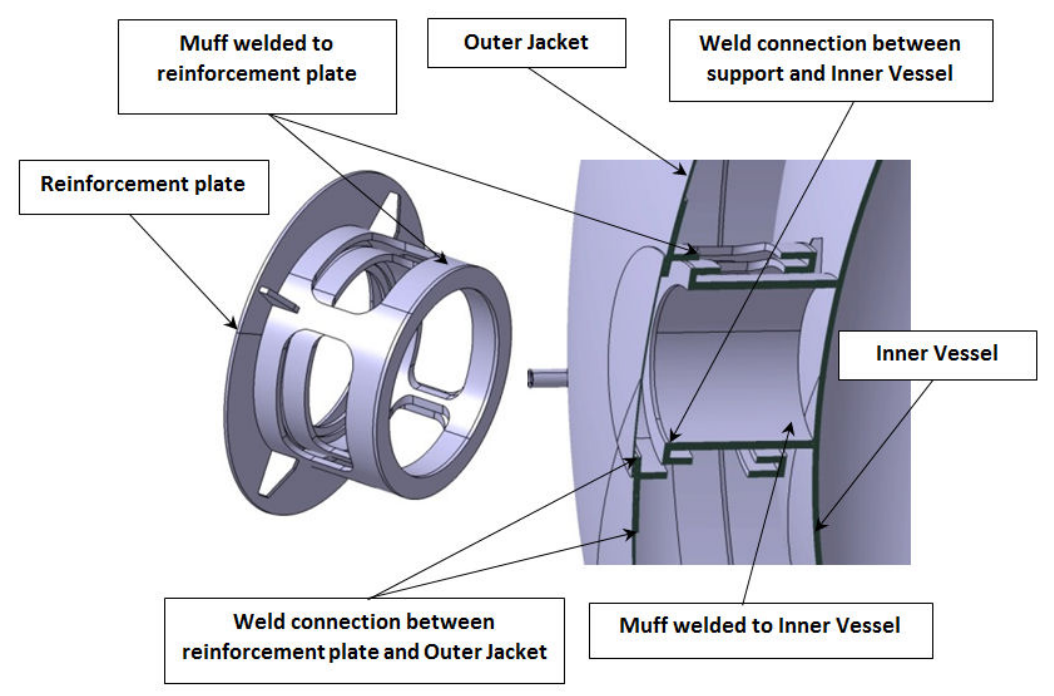

Figure 5. Example of internal supports with marked locations for welded connections to the outer jacket. Design developed by the authors.

Another important aspect of the design of the LNG tank for maritime application is the dynamic behavior of the LNG liquid itself inside the tank due to the irregular motion of the ship, called sloshing. In this case, some hydrodynamic forces and moments can appear, which can result in higher dynamic pressure and less ship stability. In order to minimize the effect of sloshing, sloshing plates (buffers) can be installed. Examples of this type of plate are presented in Figure 6.

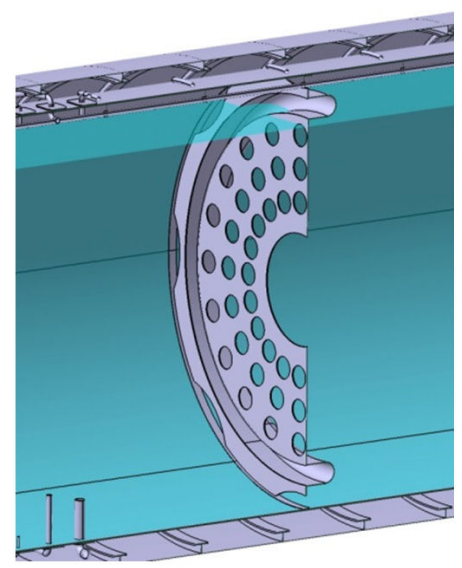

Figure 6. Examples of sloshing plates. Design developed by the authors.

Designing effective sloshing plates can be challenging. On one hand the plate must limit fluid movement (hydrodynamic aim) and also needs to be strong enough to carry the hydrodynamic forces and moments; on the other hand, the plate should not generate additional stress on the inner tank shell due to thermal shrinkage.

In order to determine the flow and pressure distribution on the sloshing plate, a Computational Fluid Dynamics (CFD) simulation for different LNG levels inside the inner tank must be performed. The results of these calculations provide us with the hydrodynamic forces due to the pressure difference between the buffer sides, which can be further used in the Finite Elements Method (FEM) of mechanical calculations.

It can be concluded that, due to very specific operation conditions that are related to the offshore application and use of mediums that require very low, cryogenic temperatures, the LNG fuel systems 
for maritime ships require special design and fabrication processes. Both processes must incorporate the following aspects:

- determination of the thermal and mechanical (especially fatigue) loads with the use of sophisticated numerical calculation methods and tools;

- selection of materials that can withstand such loads;

- thermo-mechanical optimization of selected system components, especially mechanical internal supports for the process (cryogenic) tank;

- selection of the appropriate materials for LNG tank thermal insulation and expert "know-how" related to proper installation during the tank fabrication process.

\section{LNG in Land Transport}

Safety is one of the main challenges associated with the operation of LNG-powered vehicles. A truck or bus that is equipped with a tank filled with large amounts of an extremely flammable substance must be subjected to a thorough risk analysis. Among the most important factors that should be taken into account in the event of an accident are the risk of fire hazards and tank leakages.

Designing LNG tanks for road applications requires more attention than it does for stationary solutions. In addition to the pressure and cryogenic temperature loads, the impact of the vehicle's movement should also be taken into account. In particular, the vehicle's tank should be able to withstand the loads resulting from accelerations along and across the direction of travel (see Figure 7). The values of acceleration depend on the type of vehicle and range from $\mathrm{a}_{\mathrm{x}}=5 \mathrm{~g}$ and $\mathrm{a}_{\mathrm{z}}=6.6 \mathrm{~g}$ for large trucks to $\mathrm{a}_{\mathrm{x}}=8 \mathrm{~g}$ and $\mathrm{a}_{\mathrm{z}}=20 \mathrm{~g}$ for passenger vehicles.

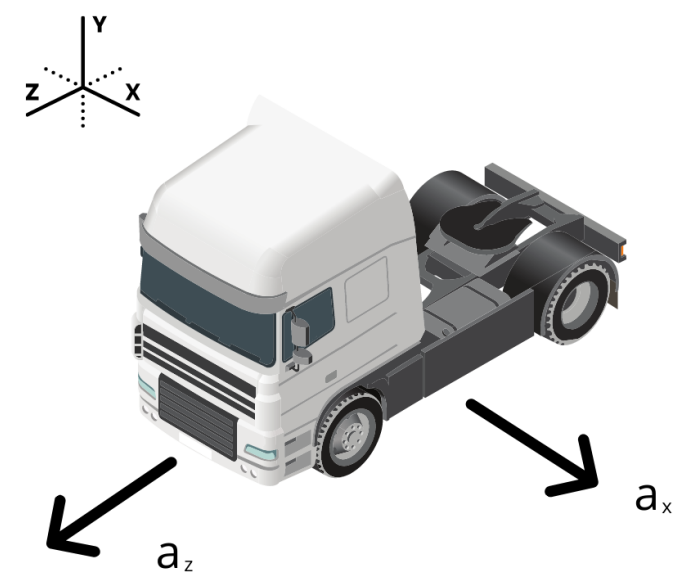

Figure 7. Accelerations acting on a truck due to movement.

The service life of the LNG tank is usually estimated to be 15 to 20 years. Therefore, the second most important aspect of tank design is fatigue strength. In particular, the number of refuelings, the conditions of use and the suspension characteristics of the vehicle should all be taken into account.

The LNG fuel tank should also be subjected to a drop test and a bonfire test, in order to measure the tank's degree of resistance to serious damage. According to [27], the drop test consists of the tank free falling from a height of $3 \mathrm{~m}$ or $9 \mathrm{~m}$ onto a concrete flat surface, depending on the piping orientation during the fall. During the test, the tank should be completely filled with liquid nitrogen at half the working pressure. After the drop, the tank must show no leaks for at least $1 \mathrm{~h}$. During the fire test, a fully filled tank with LNG at saturation pressure is exposed to a temperature of at least $590{ }^{\circ} \mathrm{C}$, as shown in Figure 8. The bonfire test is approved if the time to open the safety valve is no less than $5 \mathrm{~min}$. According to some other standards, the LNG tanks may be subjected to even more restrictive tests such as a puncture test with a machine gun. 

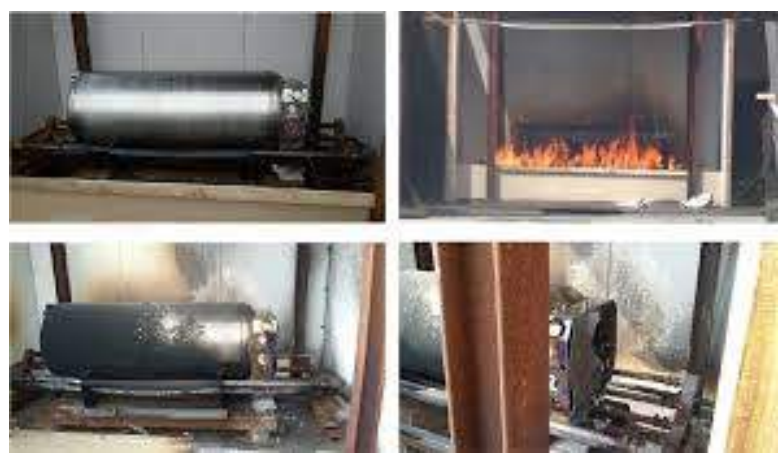

Figure 8. LNG tank during the bonfire test [28]. Test is accepted if the holding time in a temperature of at least $590{ }^{\circ} \mathrm{C}$ is not less than $300 \mathrm{~s}$.

Despite the potential dangers associated with the explosive nature of LNG, no LNG tank explosions have been reported to date. Even in the event of a serious accident, the vehicle structure and tank design have proven safe. Figure 9 shows an example of a serious collision in which the vehicle was completely burned down, but the LNG tank showed no signs of leakage.

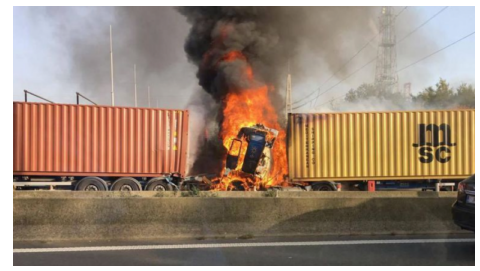

(a) Burning vehicle

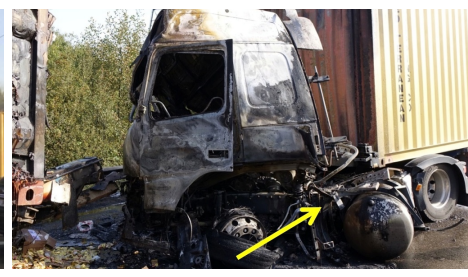

(b) Vehicle destroyed and burned due to collision

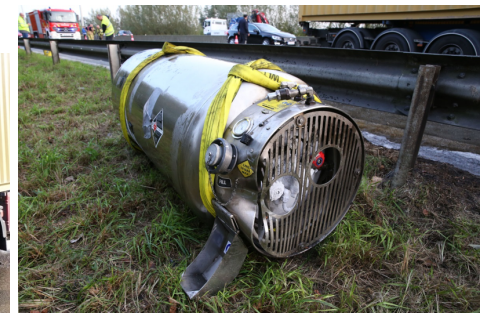

(c) LNG tank from burned vehicle

Figure 9. LNG-powered vehicle after collision and fire [29].

Dual-fuel engine supply systems are commonly used in the automotive segment. The mono-fuel system, in which LNG is the only fuel, uses spark-ignition engines implementing the Otto cycle. LNG can also be used in diesel engines, but due to the relatively high auto-ignition temperature, this requires a high degree of compression in the engine up to several hundred bars. For this reason, additional fuel is used to auto-ignite at a lower pressure and provide the necessary heat to start the LNG ignition. Systems like this are often called dual-fuel systems. The fraction of LNG in the total fuel dose ranges from $50 \%$ to $90 \%$ depending on the system design. The advantage of systems with a smaller fraction of LNG lies in their ability to operate only on diesel. The high-pressure requirement can be achieved by means of a cryogenic pump, which can be integrated with the LNG tank. This allows the overpressure in the fuel tank to be maintained at a level not exceeding 3 bar. A diagram of a tank with an internal LNG pump is shown in Figure 10.

An advantage of the single-fuel system compared with dual-fuel systems is in the reduction of harmful emissions. However, due to the very limited number of LNG stations (280 in Europe [12]), servicing such vehicles requires very careful route planning. This gives some advantage to dual-fuel vehicles, which in the absence of LNG can operate on diesel only.

In systems where LNG is the only fuel, a fuel pump is not needed, although it is necessary to maintain the appropriate overpressure in the tank. Typically, the pressure in the tank should be between 8.5 and10.5 bar(g). It should be taken into account that external heat delivered to the LNG will cause pressure to increase, while fuel consumption will cause the pressure to drop. Even in the most well-insulated tanks, a portion of the external heat will be delivered to the LNG. In the case of low fuel consumption, this amount of heat may be sufficient to maintain the required pressure. Systems with higher fuel consumption must be equipped with additional instrumentation, called a pressure build up unit (PBU), to maintain the pressure at the required level. The PBU ensures that a portion of the 
LNG after evaporation is returned in gaseous form back to the tank to compensate for the pressure drop, as shown in Figure 1.

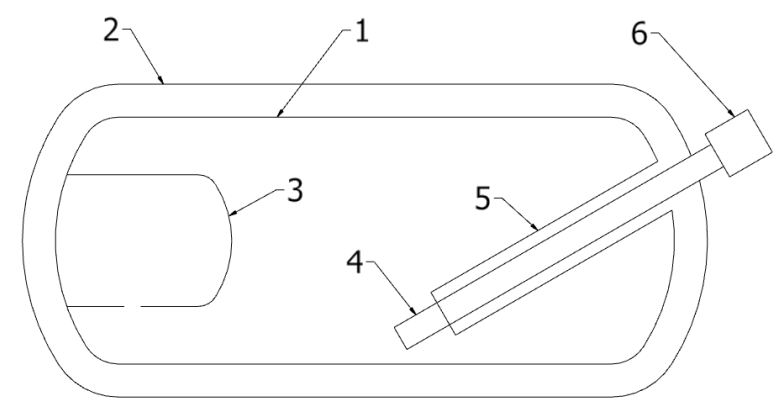

Figure 10. The LNG fuel tank with internal pump [30]: 1—process tank; 2-vacuum jacket; 3-ullage tank; 4-LNG pump; 5-pump vacuum jacket; 6-hydraulic motor.

An important parameter that affects the safety of LNG installations, and which also enables the quality of the tank insulation to be determined, is holding time. This is the amount of time it takes for the pressure to increase from the design filling pressure to the opening pressure of the main safety valve. The minimum amount of time specified by the applicable regulations is 5 days [27]. Assuming the same safety valve, heat input and amount of stored LNG are considered, this requirement is much easier to fulfill in dual-fuel installations. This is due to the significantly lower operating pressures and filling pressures in these systems. Alternatively, achieving the same holding time in a dual-fuel system is also possible with a much lower safety valve pressure setting, which can significantly simplify the design of the tank.

Another important issue related to the operation of LNG systems refers to control of the tank filling level. In order to achieve the required holding time, the tank cannot be completely filled. There must be some free space left to prevent pressure from rising too quickly if there is no fuel uptake from the tank. In the case of LNG evaporation, the gas in the free space is slowly compressed. This free space can be maintained by the introduction of a ullage tank inside the LNG tank, as shown in Figure 11.

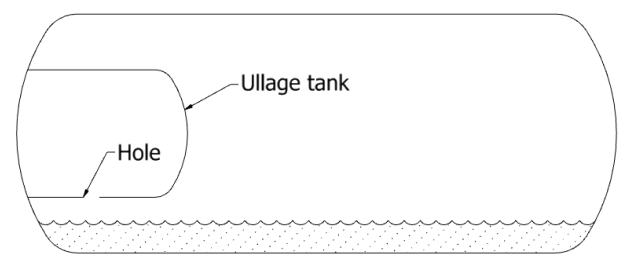

(a) Before refueling

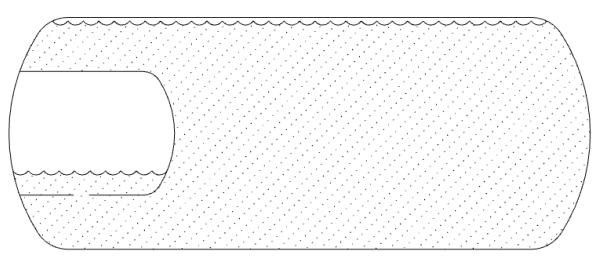

(b) After refueling

Figure 11. Ullage tank working principle.

The ullage tank is connected to the fuel tank by a small passage at its lowest point and is filled with LNG vapor before refueling. During refueling, only a small amount of LNG can enter, and this is due to the increasing vapor pressure accumulating in the ullage tank and the high local resistance of the passage. When the tank is full, the ullage tank provides the required free volume. In order to ensure proper operation of the system, the volume of the ullage tank and the size of the passage must be correctly designed.

According to industry forecasts, the number of LNG-powered vehicles will increase significantly in the near future. Therefore, the construction of fuel installations is carried out in accordance with very restrictive standards and subjected to very rigorous testing. It should be noted that, to date, no serious incidents with LNG vehicles have been reported. 


\section{Exergy Recovery in Mobile Applications}

\subsection{LNG Cold Exergy Recovery Methods for Mobile Systems-Overview}

According to [31], exergy is the maximum amount of work that can be extracted from a sub-system as it approaches thermodynamic equilibrium with its surroundings by a sequence of reversible processes. LNG exergy per unit of mass can be calculated assuming that the cold exergy is equal to the minimum work required for the condensation of natural gas from ambient temperatures. Total exergy consists of thermal exergy and pressure exergy [32,33] and can be formulated as follows [32]:

$$
E_{X}=h(T, p)-h_{0}(T, p)-T_{0}\left[s(T, p)-s_{0}(T, p)\right]
$$

where $h(T, p)$ is the enthalpy of $L N G, h_{0}(T, p)$ is the enthalpy of NG in equilibrium with surrounding, $T_{0}$ is the surrounding temperature, $s(T, p)$ is the entropy of LNG and $s_{0}(T, p)$ is the enthropy of NG in equilibrium with the surroundings.

The exergy of LNG at normal pressure can be calculated using Equation (2). For this purpose, the boiling temperature of LNG is assumed to be $109 \mathrm{~K}$ with a surrounding temperature of $293 \mathrm{~K}$. The resulting exergy of LNG at these conditions is $1040 \mathrm{~kJ} / \mathrm{kg}$ [34]. Similar calculations can be repeated to estimate the available LNG exergy for different mobile applications. The results are shown in Table 1.

Table 1. Example of available exergy of LNG at 1 bar pressure in mobile applications.

\begin{tabular}{ccc}
\hline Application & LNG Consumption, kg/h & Exergy Flux, kW \\
\hline road & 10 & 2.9 \\
rail & 300 & 86.7 \\
marine & 2000 & 577.8 \\
\hline
\end{tabular}

Despite several attempts to use cold LNG exergy to cool the air at the engine inlet [35], in cargo space and passenger compartments [36,37] or to run a thermal LNG pump [35], in most mobile applications, LNG is still being regasified without recovering the cold energy.

The utilization of cold exergy for cooling applications is relatively simple and is based on the physical exergy of LNG. The amount of available cooling power is equivalent to the heat needed for LNG regasification, $1010 \mathrm{~kJ} / \mathrm{kg}$ [33]. In terms of mobile applications, the primary usage of physical exergy may be dedicated to food cooling and freezing [38]. It can also potentially be applied in LNG-fueled trucks or ships, as well as in air conditioning, the production of dry ice [39] and in freezing desalination [40].

The main advantage of direct cooling is in the simplicity of the system, since most components are easily accessible. The disadvantage of such a system is in the significant degradation of thermal exergy because the boiling point of LNG is much lower than the temperature of food storage. As a consequence, exergy recovery is low.

Low-temperature exergy can also be recovered by conversion to electricity. Conversion can be achieved indirectly by means of a thermodynamic power cycle or directly by means of thermoelectric generators (TEGs). Indirect conversion is based on the assumption that the compression work in lower temperatures or in liquid state is much lower than the expansion work in higher temperatures in gaseous state. These conditions can be obtained if LNG pressure is increased prior to regasification and directed to the expander post-regasification. This is called the Direct Expansion System [41]. Another possibility is to use the LNG as a low-temperature heat sink in the Organic Rankine Cycle or Brayton Cycle. These systems can be effective, but they are also complex and mostly used in stationary applications [42-46].

Direct conversion to electricity can be accomplished using thermoelectric generators. A thermoelectric generator is a device that uses the thermoelectric effect (Seebeck effect) caused by differences in temperature $[47,48]$. The generated electricity can be directly used to power any external 
devices. The main advantage of using TEGs lies in their flexibility and all their possible applications at the micro and macro scales, which can make them particularly useful in mobile applications [49].

Thermal gas compression is another way to use the low-temperature exergy of LNG. LNG as a fuel is stored in a cryogenic tank. When the vehicle is powered, natural gas is passed to the engine. In the event of a stoppage or an emergency, LNG is not released from the tank and the pressure increases due to external heat flows. After exceeding the allowable holding time, the excess LNG steam must be released (e.g., through an external burner). Another possible option is to allow partial gas discharge to another tank and apply thermal gas compression. To avoid energy consumption during compression, the absorbed natural gas (ANG) method can be used instead. ANG is based on NG adsorption in a low-temperature bed. The bed can be cooled with a stream of LNG. In an emergency, the pressure in the main tank can also be lowered via the thermal compression of excess natural gas. This allows the natural gas to be released under higher pressure by heating the ANG bed, and then it can be safely stored. It is highly probable that in the case of an emergency stoppage, holding time can be significantly exceeded by means of the ANG.

For rail or road transport, the holding time is required to last longer than five days [50]. The holding time significantly exceeds the potential travel time of the service team. This means that towing a damaged vehicle or pumping natural gas out of the fuel tank is much more justified than using ANG.

Table 2 summarizes the possible methods of exergy recovery along with their applicability in mobile applications and the main conclusions.

Table 2. LNG low-temperature exergy recovery methods overview [36,37,41-46,49].

\begin{tabular}{ccl}
\hline $\begin{array}{c}\text { Recovery } \\
\text { Method }\end{array}$ & $\begin{array}{c}\text { Applicable for } \\
\text { Mobile } \\
\text { Applications }\end{array}$ & Notes \\
\hline Direct cooling & Yes & low efficiency, simplicity, component availability \\
Direct expansion & No & low efficiency, supervision required \\
Organic Rankine Cycle & No & high efficiency, complexity, supervision required \\
Brayton Cycle & No & high efficiency, complexity, supervision required \\
Thermoelectric Generator & Yes & low efficiency, simplicity, low maintenance, scalability \\
ANG Method & Marine: Yes & simplicity, low maintenance \\
& Rail \& Road: No & \\
\hline
\end{tabular}

\subsection{Exergy Recovery Using Thermoelectric Generators}

Thermoelectric generators (TEGs) make the direct conversion of thermal energy to electricity possible. The principle of operation of TEG is based on the Seebeck effect, as shown in Figure 12a. $A$ junction of two metals, or semiconductors $A$ and $B$, is made and set in a temperature of $T_{1}$. The other ends of $A$ and $B$ are set in a different temperature, $T_{2}$. The temperature difference between $T_{1}$ and $T_{2}$ generates the electromotoric force (EMF). The EMF depends on the material properties and the value of the temperature difference. Figure $12 \mathrm{~b}$ shows a schematic view of the TEG module. In practice, the TEG modules can be set in a series of multiple junctions to increase their power.

The major disadvantage of TEG is the low energetic efficiency. The efficiency of thermoelectric module depends on the type of material used and the operating temperature. It can be described with thermoelectric figure of merit (ZT):

$$
\mathrm{ZT}=\frac{\mathrm{S}^{2} \sigma \mathrm{T}}{x}
$$

where $S$ is the Seebeck coefficient $(\mu \mathrm{V} / \mathrm{K}), \sigma$ is the electrical conductivity $(1 / \Omega \mathrm{m}), \mathrm{T}$ is the average temperature $(\mathrm{K})$ and $x$ is the thermal conductivity $(\mathrm{W} / \mathrm{mK})$. 


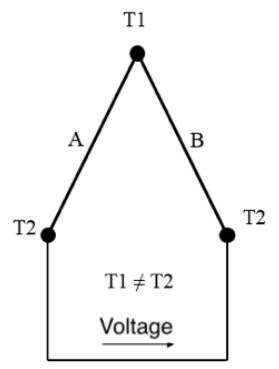

(a) Thermoelectric effect

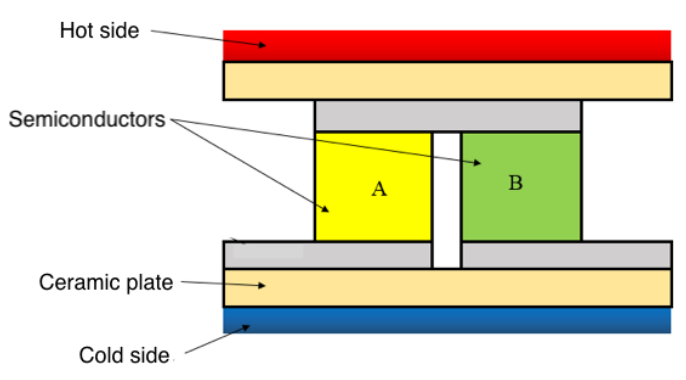

(b) Thermoelectric generator (TEG) module

Figure 12. Thermoelectric generator working principle.

Thermoelectric modules are commonly used in temperatures ranging from room temperature to higher temperatures. The energetic efficiency (defined as the electric power output divided by the heat flux through the TEG module) of TEGs working in temperatures above $300 \mathrm{~K}$ is typically around $5 \%[47,51]$.

In the case of LNG-powered mobile applications, heat from the cooling system of the engine can be used as a heat source. To provide the required heat flux, TEG can be placed on the LNG line, between the LNG tank and the main vaporizer, as shown in Figure 13.

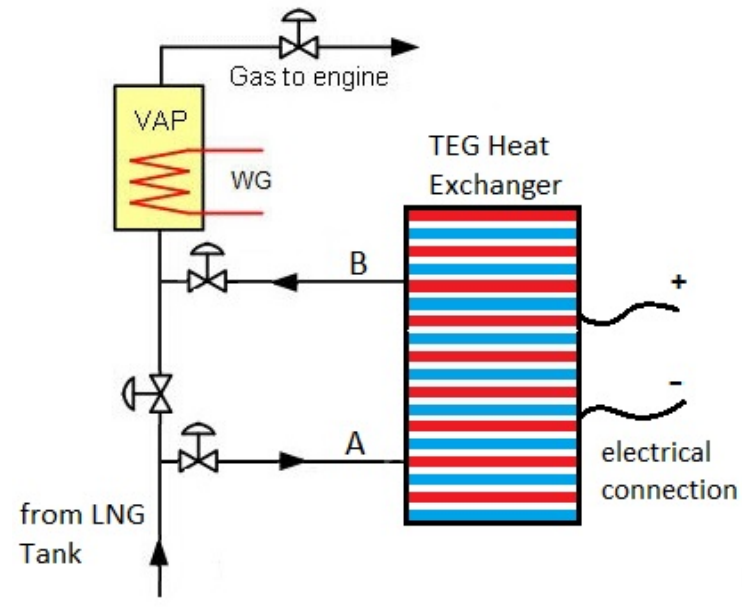

Figure 13. An exemplary connection of the TEG system to the main LNG Tank.

Use of the thermoelectric effect in the LNG regasification process is not clear because very low temperatures $(<200 \mathrm{~K})$ can be unfavorable [51]. On the other hand, a significant temperature difference should have a favorable influence on TEG performance [48].

\subsection{ANG Technology in Marine Transportation}

As mentioned in the previous subsection, in the case of marine applications, the recovery of LNG exergy using the ANG method involves cooling the adsorption bed. During normal engine operation, cooling can be done with cold vapors. This can prepare the adsorbent for emergency storage in the case of gas overproduction.

The main part of the ANG system is a tank with a carbon adsorbent. The tank has two pairs of connections. One pair is connected to the coil inside the adsorption tank and is used to cool the coal bed and transfer LNG to the main heat exchanger. The second pair is connected to the adsorbent chamber that has been filled with the activated carbon adsorption bed and used to store the natural 
gas, which can be used to power the engine. The exemplary connection of the ANG tank to the main LNG tank (see Figure 1) is shown in Figure 14.

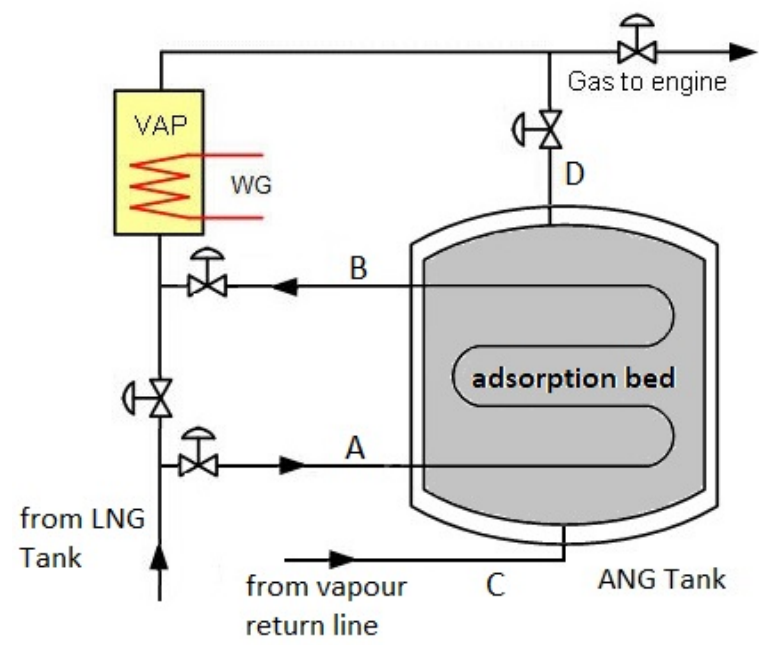

Figure 14. An exemplary connection of the absorbed natural gas (ANG) tank to the main LNG tank.

During nominal engine operation, the LNG stream flows from the LNG tank through line A (see Figure 14) to the coil inside the adsorption tank. LNG partially evaporates by cooling the adsorption bed and prepares it for the adsorption process. The stream of NG flows through line B to the vaporizer (VAP in Figure 14) and feeds the engine. In the case of engine failure, with danger of exceeding the holding time, the NG vapor from the LNG tank is supplied to the cooled bed of the ANG tank using line C (see Figure 14). This reduces the pressure (and thus the temperature) in the LNG tank, and the holding time is increased. The adsorbent bed reheats in a natural way to ambient temperature, which causes an increase in the NG pressure to about 40 bar by means of thermal compression. From then on, the ANG tank is treated as an additional fuel tank ready to transfer NG to the engine using line D (see Figure 14).

For successful implementation of the ANG method, knowledge of natural gas adsorption characteristics for various temperatures and pressures is required. The temperature inside the ANG tank can vary from $150 \mathrm{~K}$ to $300 \mathrm{~K}$ and the pressure from 6 bar to 40 bar. Although in the scientific world, there are some attempts to determine adsorption isotherms for the temperatures of liquid natural gas [52], most of the adsorption beds are not examined for natural gas adsorption in temperatures below $270 \mathrm{~K}$. The ANG technology can potentially replace a standard gas compressor, and instead of electricity, the available cooling capacity from LNG regasification can be used. Taking into account the expected energy gain, research on the natural gas storage system with the use of adsorption beds should be performed.

\section{Re-Condensation System}

\subsection{Introduction}

A re-condensation system (RcS) is an autonomous installation dedicated to either achieving or extending the holding time of the LNG fuel tank. The capacity of the RcS compensates for heat inflow to LNG via insulation and other elements of the tank. Cooling power is transferred to the system by the process of BOG (boil off gas) liquefaction.

Re-condensation and fuel installations are thermally coupled by a heat exchanger connected to the system either directly or through process pipes to allow BOG circulation to and from the tank. The Vapor Return Line transports boil off gas to the heat exchanger, while the Bunkering Line returns condensate back to the tank, see Figure 1. 
Figure 15 presents the capacity of the re-condensation systems required for mobile applications (both marine and land installations).

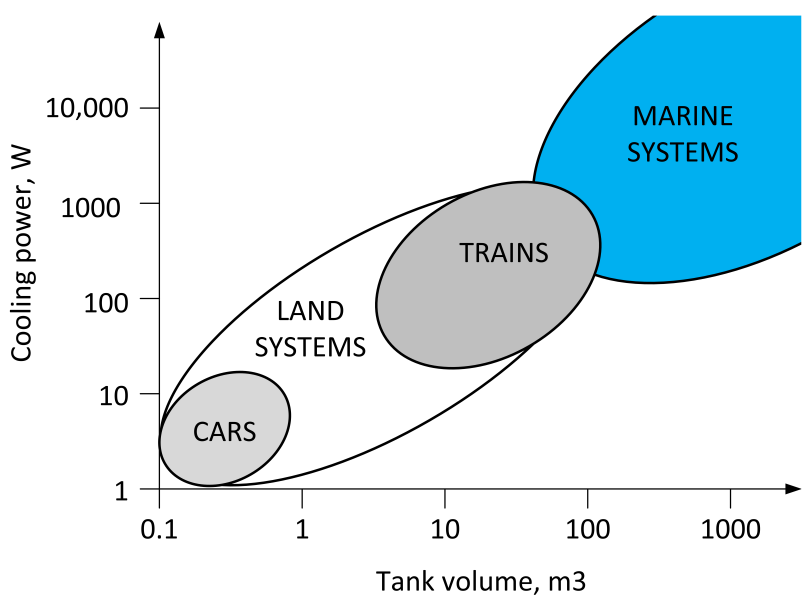

Figure 15. Capacity of the re-condensation system vs. tank volume for marine and land installations.

The demanded cooling power of the systems depends on the working pressure, volume (construction) and insulation of the LNG fuel tank. With working pressure assumed to be at 6 bar and with the daily evaporation rate at $0.15 \%$ of the tank volume, land applications require up to $10 \mathrm{~W}$ for a car/truck and up to $1 \mathrm{~kW}$ for a train, whereas marine applications demand at least $0.5 \mathrm{~kW}$ up to more than $10 \mathrm{~kW}$ of cooling power produced at cryogenic temperatures.

\subsection{System Configuration}

Cooling power can be transferred to BOG in two ways: through a heat exchanger that is installed either inside or outside the LNG tank. The first configuration, with an internal heat exchanger, allows gravity-based BOG circulation. Boil off gas surrounds the heat exchanger while droplets of condensate naturally fall into the liquid. A re-condensation system with an internal heat exchanger and a gravity-based BOG cycle is presented in Figure 16 and a system with an external heat exchanger and a forces BOG cycle is shown in Figure 17.

Figure 18 shows thermodynamic processes in a T-s diagram for the gravity-based and forced BOG cycles. Processes 1-2 correspond to the gravity-based BOG shown in Figure 16, and cycles 1-2A-3A-4A-5A correspond to the forced BOG shown in Figure 17. The main advantages of a re-condensation system with internal heat exchangers are its simple construction and lack of pressure components (compressors) or liquid pumps. The main disadvantage is related to the temperature of the cooling power $\mathrm{T}_{\mathrm{R}-\mathrm{BOG}}$, which must be lower than the temperature of the BOG process $\mathrm{T}_{\mathrm{BOG}}$ at $\mathrm{p}_{\mathrm{LNG}}$ (processes 1-2 in Figure 18). Lowering the temperature of the cooling power $\mathrm{T}_{\mathrm{R}-\mathrm{BOG}}$ directly affects the thermodynamic efficiency of the cryocooler and consequently reduces the efficiency of the re-condensation system.

Figure 17 presents the idea of a BOG cycle that is forced by a compressor. The process

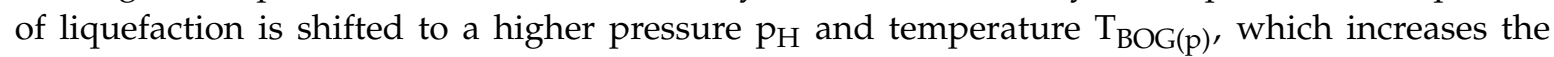
thermodynamic efficiency of the cryocooler, but which also requires additional work to compress the BOG. Pressurized BOG (point 2A in Figure 18) flows through the external heat exchanger and is cooled down to $T_{3 \mathrm{~A}}$ (saturation temperature) and then liquefied (isobaric processes $3 \mathrm{~A}-4 \mathrm{~A}$ ). The saturated condensate must be expanded from a pressure of $\mathrm{p}_{\mathrm{H}}$ (point $4 \mathrm{~A}$ ) to a pressure of $\mathrm{p}_{\mathrm{LNG}}$ in the LNG tank. The liquid flowing through the throttle valve (processes $4 \mathrm{~A}-5 \mathrm{~A}$ ) partially evaporates (an effect of partial/flash evaporation). 


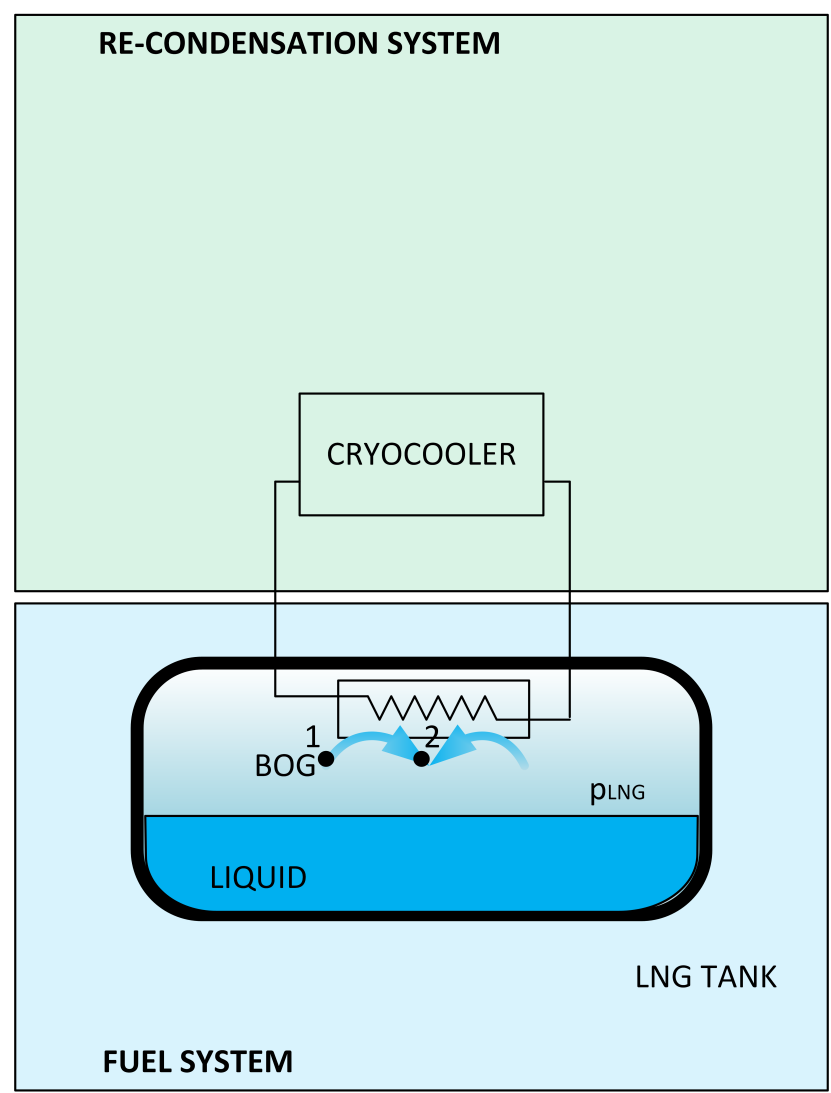

Figure 16. Re-condensation system with internal heat exchanger and gravity burn off gass (BOG) cycle.

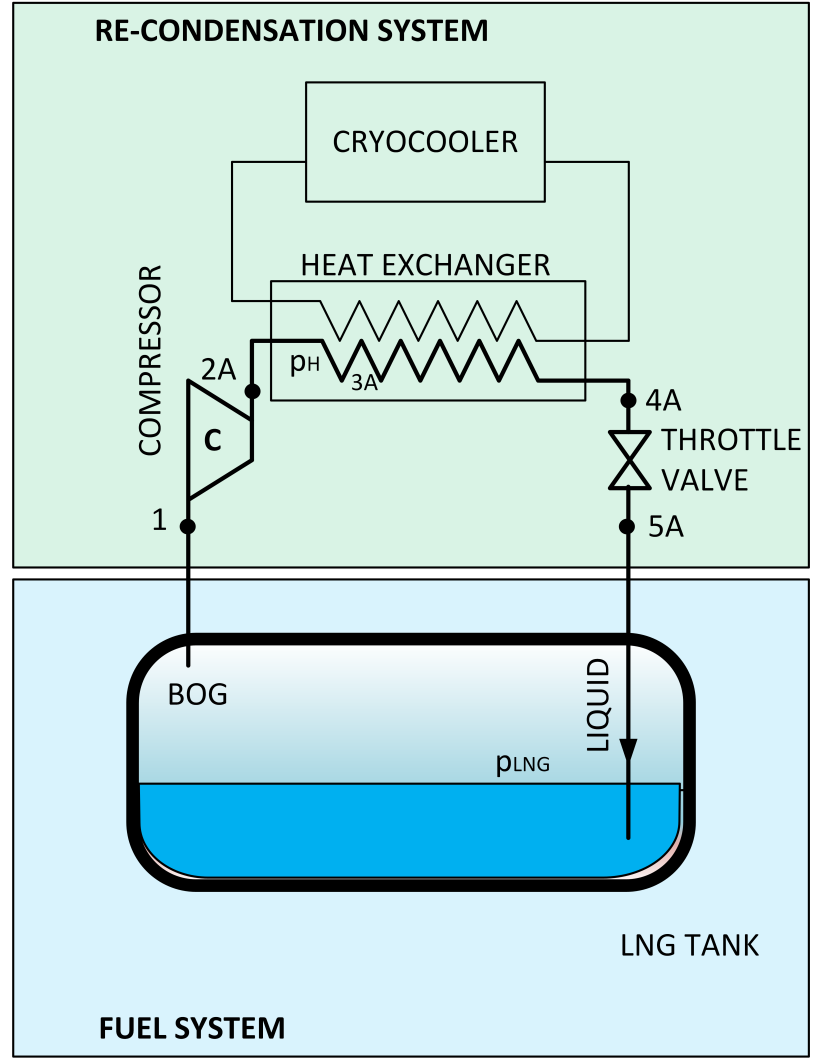

Figure 17. Re-condensation system with external heat exchanger and forced BOG cycle. 


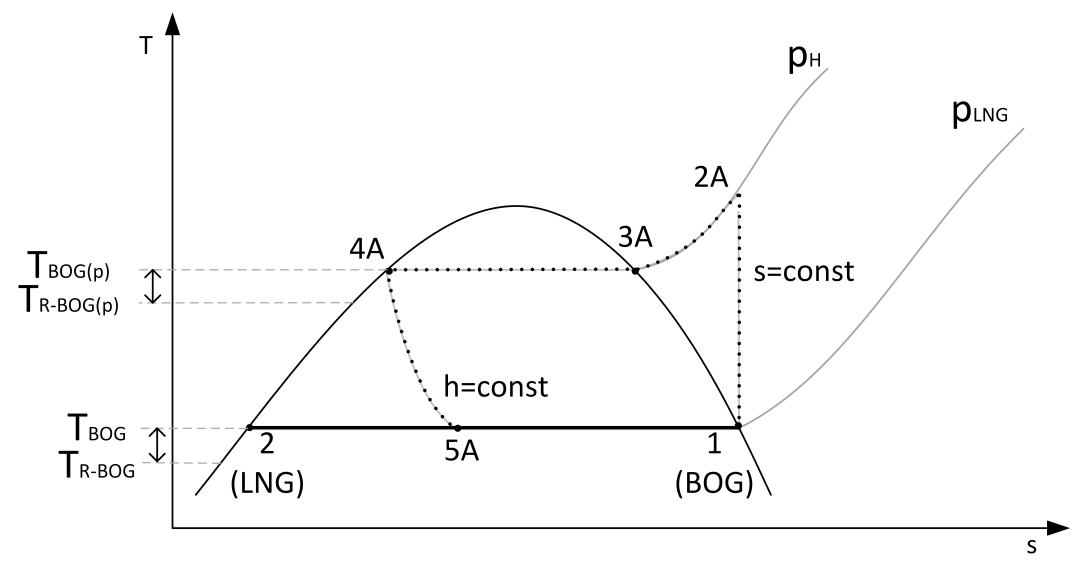

Figure 18. Thermodynamic processes for the gravity and forced BOG cycle.

The main advantage of the forced BOG cycle is in the higher thermodynamic efficiency of the cryocooler, which corresponds to a temperature of $\mathrm{T}_{\mathrm{BOG}(\mathrm{p})}$. Moreover, the external heat exchanger makes the re-condensation system more flexible because it does not have to be installed close to the LNG tank. The main disadvantage, in addition to the higher investment cost, is flash (or partial) evaporation that occurs during the throttling process of the saturated liquid.

\subsection{Energy Analysis of the Re-Condensation System Configurations}

\subsubsection{Gravity BOG Cycle}

Cryocoolers transport the heat from a low-level temperature to a high-level (ambient) temperature. Therefore, they require work input, which depends on the temperature difference. BOG in the gravity circuit is liquefied at the level of LNG storage pressure, so the total work input to the re-condensation system is equal to the work of the cryocooler (see Figure 16) and can be expressed by Strobridge's modification of the Carnot formula [53]:

$$
\frac{\mathrm{P}_{\mathrm{A}}}{\mathrm{Q}}=\frac{1}{\mathrm{COP}_{\mathrm{C}} \cdot \% \text { Carnot }}
$$

where $\mathrm{P}_{\mathrm{A}}$ is the input power for the actual cryocooler, $\mathrm{Q}$ is the cooling effect, $\mathrm{COP}_{\mathrm{C}}$ is the coefficient of performance for Carnot cooler and \%Carnot is the percent of Carnot.

The percent of Carnot (\%Carnot) indicates how much the actual cooler deviates from ideal performance. According to the Strobridge plot, actual cryocoolers producing cooling power between 10 and $100 \mathrm{~W}$ at $90 \mathrm{~K}$ (potentially for car re-condensation systems) can achieve approximately $10 \%$ of the Carnot efficiency, whereas cryocoolers providing between 100 and $1000 \mathrm{~W}$ (train system), or above $1000 \mathrm{~W}$ (marine system), can perform at $12-15 \%$ up to $30 \%$ efficiency, respectively. Figure 19 presents the total input power required to produce $1 \mathrm{~W}$ of cooling power in the case of land and marine re-condensation systems and for the gravity-based BOG cycle. The analysis was performed by the authors.

According to Strobridge [53], the actual efficiency of the cryogenic cooler increases with its capacity. Therefore, the cost of $1 \mathrm{~W}$ of cooling power for a low-capacity car system is about 3 times higher than it would be for marine applications and 1.5 times higher than it would be for train installations. In conclusion, the re-condensation system, without changing the BOG pressure, is more economical in terms of the input work demand for high-capacity systems. 


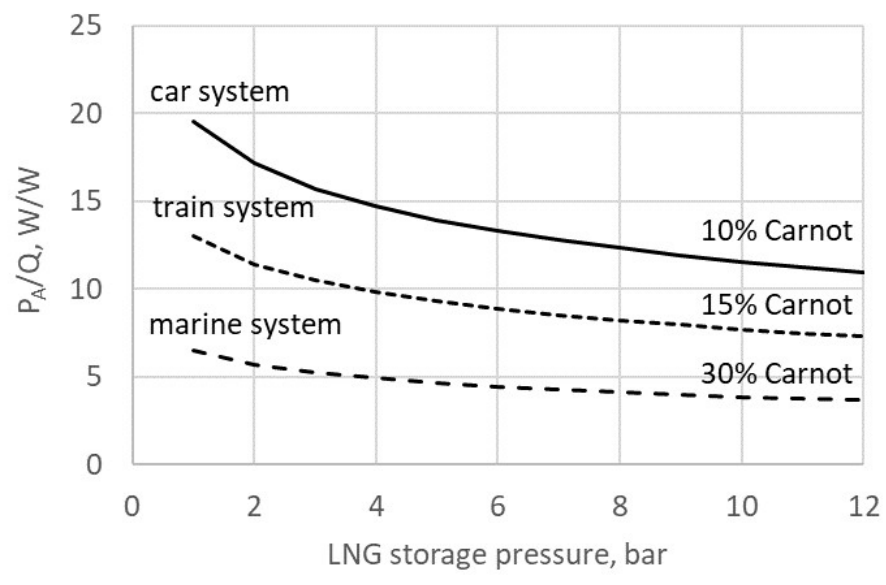

Figure 19. Input power demand for re-condensation systems as a function of LNG storage pressure.

The analysis was performed by the authors.

\subsubsection{Forced BOG Cycle}

The total input work $\mathrm{w}_{\mathrm{T}}$ of the forced BOG cycle system is the sum of the input work of the cryocooler, calculated using Equation (4) and the input work of the BOG compressor. The work of the cryocooler should include the partial (flash) evaporation, and the work of the BOG compressor can be calculated as isentropic compression work with a process efficiency of $75 \%$.

Figure 20 shows the share of the liquid phase in the function of the final pressure of the BOG. A significant reduction of the liquid phase share, resulting from the flash evaporation of the saturated liquid, is observed to be possible. The analysis was performed by the authors. In the case of LNG stored at a pressure of $\mathrm{p}_{\mathrm{LNG}}=6 \mathrm{bar}$, the pressurization of BOG leads to a reduction of the liquid phase from $98 \%$ for $\mathrm{p}_{\mathrm{H}}=7$ bar to $54 \%$ for $\mathrm{p}_{\mathrm{H}}=36$ bar. As a consequence, the flash evaporation cannot be neglected.

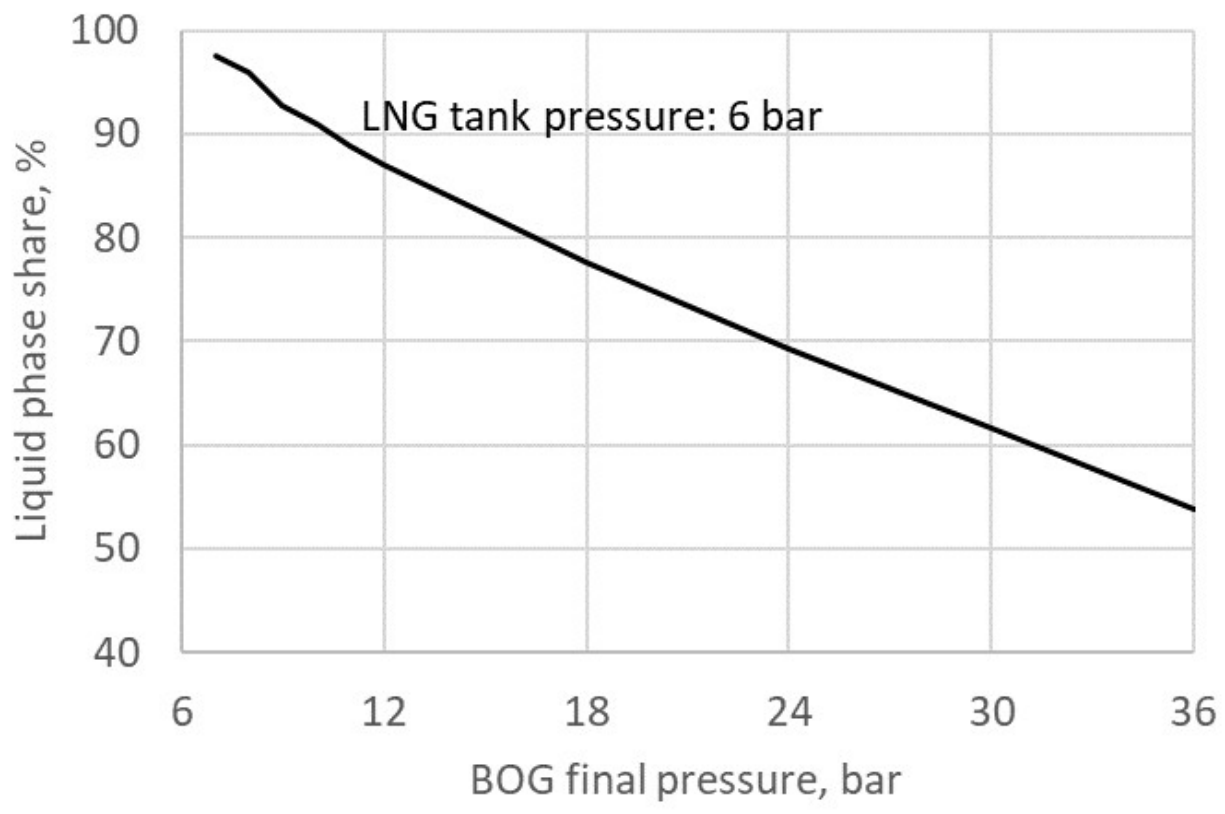

Figure 20. Liquid phase share in the mixture after throttling saturated liquid. The analysis was performed by the authors. 
Figure 21 presents the dependence of the total work of the system on the final BOG pressure in the case of the forced BOG cycle, for land and marine systems assuming $10 \%, 15 \%$ and 30\% \%Carnot, respectively. The analysis was performed by the authors. It can be seen that increasing the BOG pressure $\mathrm{p}_{\mathrm{H}}$ results in a rise in the thermodynamic efficiency of the cryocoolers but does not decrease the total input work of the system. The gain from the growth in efficiency is destroyed by the reduction of the liquid phase in the throttling process. Similarly, as in the case of the gravity BOG cycle, the low capacity of the truck and train installations combined with the low efficiency of the cryocoolers causes a high demand for total work. This makes re-condensation systems based on the forced BOG cycle uneconomical for low-capacity applications.

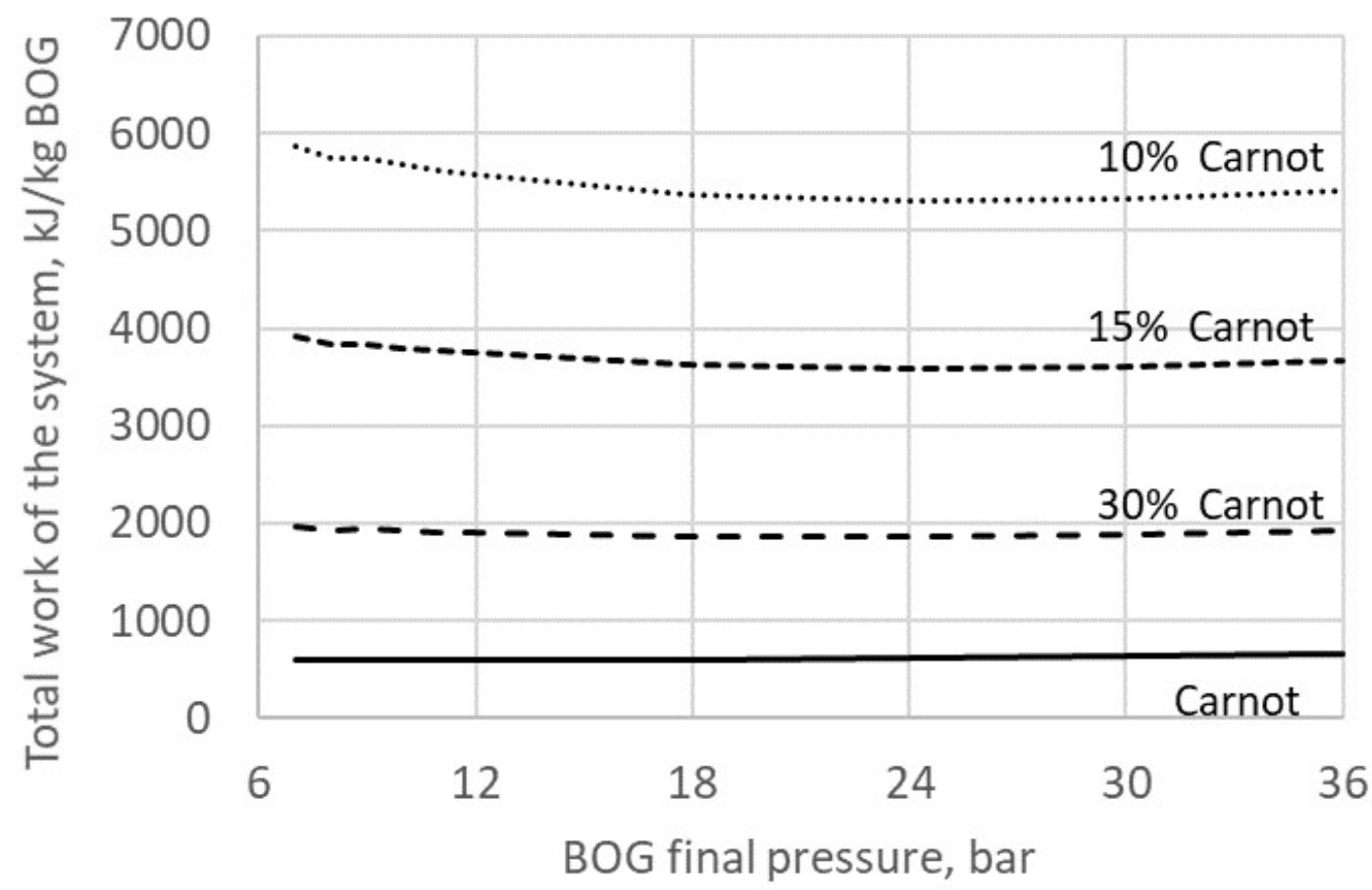

Figure 21. Total work of the system vs. final BOG pressure. The analysis was performed by the authors.

In general, re-condensation systems can be considered alternative methods of BOG utilisation $[54,55]$. They are designed to re-circulate the fuel that has evaporated due to an extensive rise in pressure inside the tank. At the same time, the input work for a re-condensation system is produced by the LNG powered engine. Therefore, the RcS is economically justified only when the stream of condensate (the liquefied BOG) is larger than the stream of the fuel used to power the re-condensation system. An analysis of the cost (LNG fuel) and product (liquefied BOG) balance can be based on the following assumptions:

1. caloric value of the LNG fuel: $35.36 \mathrm{MJ} / \mathrm{m}^{3}$;

2. efficiency of the fuel chemical energy conversion to the mechanical energy: $50 \%$ for the car/truck and $40 \%$ for the train and ship engines;

3. efficiency of the actual cryocoolers: $10 \%$ of Carnot efficiency for car $/$ truck, $15 \%$ for train and $30 \%$ for marine systems.

Figures 22 and 23 present the results of the cost analysis performed by the authors. The ratio of the product stream (liquefied BOG) to the stream of LNG fuel is shown in Figure 22. The indication "ship 30\%C/40\%E" stands for the marine system equipped with a cryocooler working with $30 \%$ of the Carnot efficiency, and an engine operating with $40 \%$ of energy conversion efficiency. 


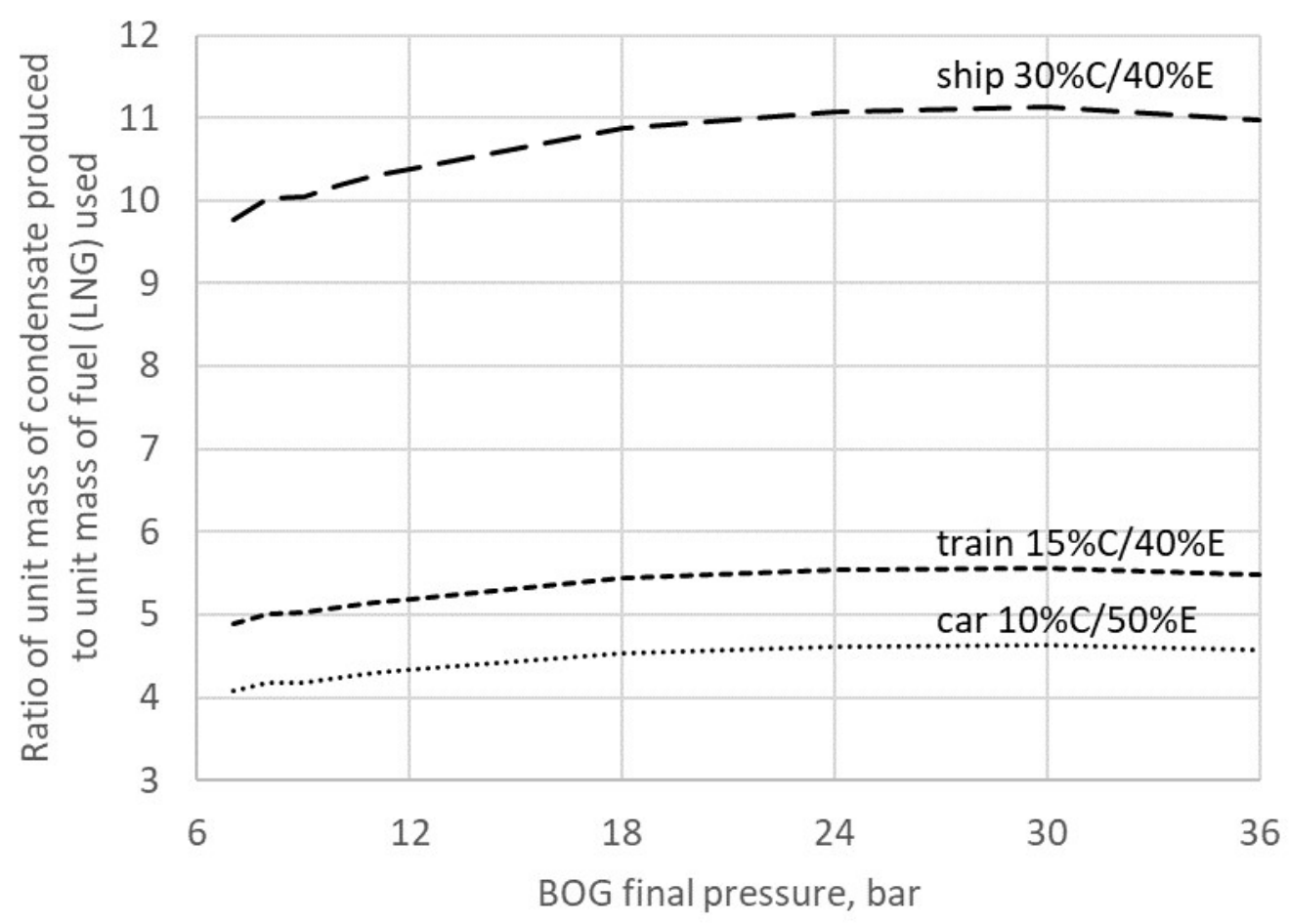

Figure 22. Product-to-fuel balance for land and marine re-condensation systems. The analysis was performed by the authors.

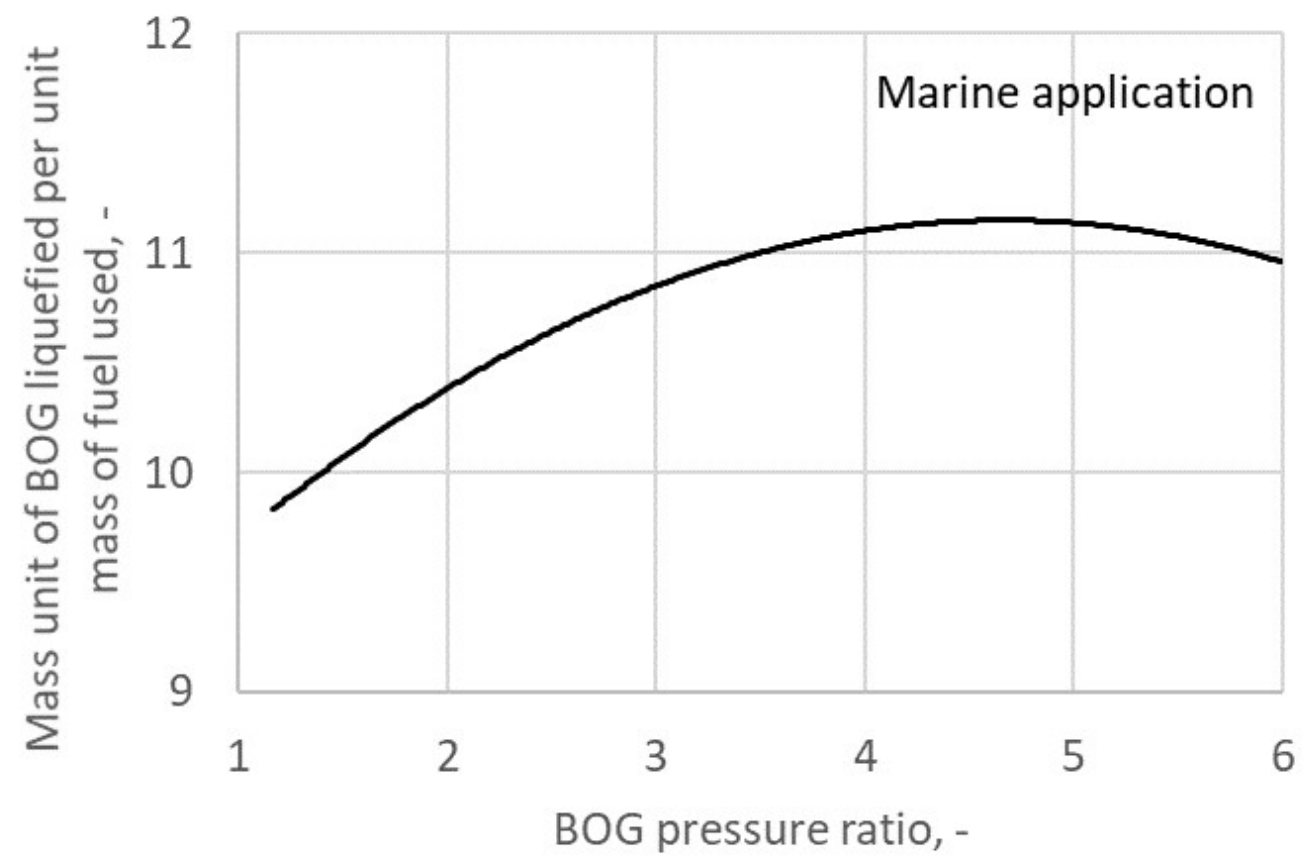

Figure 23. Product-to-fuel balance for marine re-condensation system. The analysis was performed by the authors.

According to the results presented in Figure 22, the marine re-condensation system using $1 \mathrm{~g} / \mathrm{s}$ of the LNG fuel makes it possible to liquefy approximately $10-11 \mathrm{~g} / \mathrm{s}$ of BOG. The capacity of both land systems are similar and approximately $4-5 \mathrm{~g} / \mathrm{s}$ for the entire range of the BOG pressure. Taking into 
account the high investment cost of any cryogenic cooler, re-condensation systems for car and train installations are not economically justified.

Figure 23 shows data for the marine system only. It can be concluded that re-condensation systems for marine applications seem to be an interesting and valuable method of BOG utilization. The stream of liquefied BOG is expected to be 10 times larger than the stream of used LNG. As a consequence, it can help to save a significant amount of fuel. It should be noted that re-condensation systems should operate with a pressure ratio of $\frac{\mathrm{p}_{\mathrm{H}}}{\mathrm{p}_{\mathrm{LNG}}}<4.5$.

\subsection{Overview of Cryocooler Technologies}

There are five types of cryogenic coolers that may be considered sources of cooling power for re-condensation systems. They have been listed in Table 3 together with their corresponding capacity ranges.

Table 3. Cryogenic coolers.

\begin{tabular}{lll}
\hline Cryooler & Capacity Range & \\
\hline Turbo-Brayton & $18-250 \mathrm{~kW}$ at $120 \mathrm{~K}$ & {$[56]$} \\
Stirling & $2-8 \mathrm{~kW}$ at $120 \mathrm{~K}$ & {$[57]$} \\
Gifford-McMahon & $14-600 \mathrm{~W}$ at $80 \mathrm{~K}$ & \\
2-stage Pulse Tube & up to $1.2 \mathrm{~kW}$ at $120 \mathrm{~K}$ & {$[58,59]$} \\
Single-stage Pulse Tube & $12-90 \mathrm{~W}$ at $80 \mathrm{~K}$ & \\
Miniature Pulse Tube & $3-10 \mathrm{~W}$ at $80 \mathrm{~K}$ & \\
Joule-Thomson & $100 \mathrm{~W}$ at $120 \mathrm{~K}$ & {$[60]$} \\
Cryogenic cascade & up to few kW at $120 \mathrm{~K}$ & {$[61]$} \\
\hline
\end{tabular}

Figure 24 presents a graphical summary of the available technologies that fulfill the requirements of re-condensation systems in the function of the cooling capacity. The entire range of capacity for land and marine systems is observed to be covered by commercially available cryocoolers. In summary, it can be said that a wider market availability of marine recondensation systems is expected in the near future, while truck or train systems should reduce investment costs to make them economically viable.

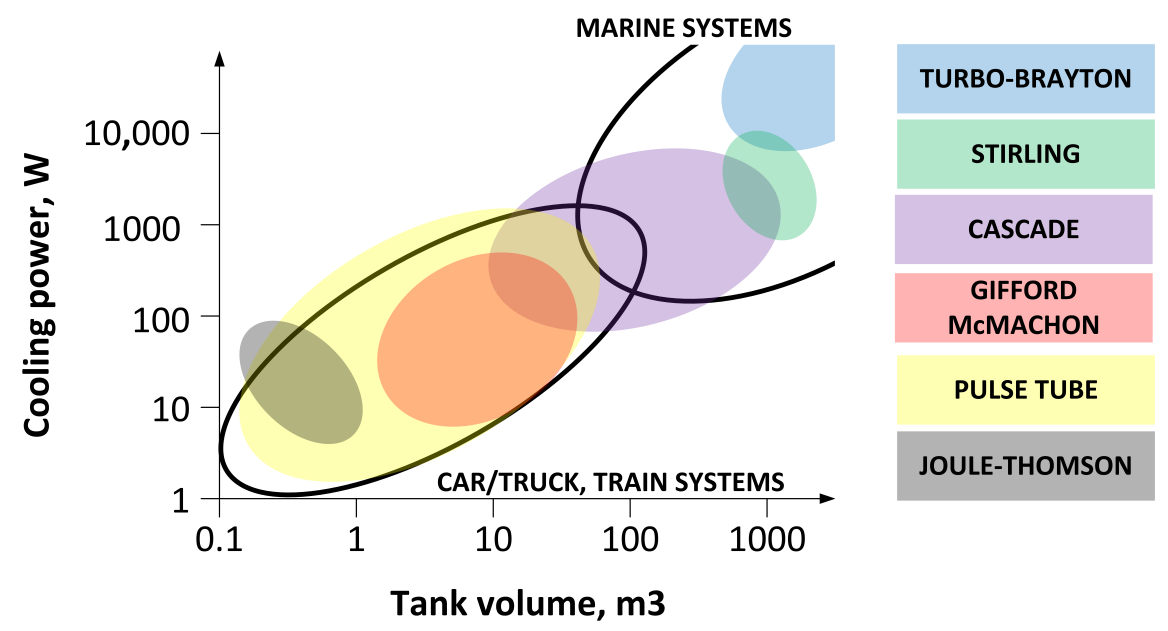

Figure 24. Availability of cryocoolers for the marine and land re-condensation systems.

\section{LNG Regasification and Chosen Challenges of LNG Two-Phase Heat Exchangers}

Liquefied natural gas has to be vaporized before it can be used as an energy source [18,62]. The low temperature of a phase change can be a source of useful cold energy, but its utilization comes with operational and safety hazards, such as the freezing of the heating agent, cryogenic pollution 
and frostbite risk [63]. The freezing of the heating agent is often identified as the main risk of the LNG regasification process [64]. In stationary applications, LNG is vaporized using Open Rack Vaporizers [63,65-67], Submerged Combustion Vaporizers [68,69] and Intermediate Fluid Vaporizers [70]. These solutions make it possible to mitigate or eliminate the freezing risk, but, on the other hand, they are not very volume-efficient or compact [71].

These features are of great importance in the case of mobile applications; therefore, in applications such as heavy trucks [62,72], railway [73] or marine transport [18], they have developed their own specific range of LNG vaporizers. However, mobile applications not only have specific requirements, but they also present the design of regasification systems with certain opportunities. On the one hand, reliable, volume- and mass-effective design is expected; on the other hand, it is possible to couple the vaporizer with the engine cooling system in LNG-fueled vehicles [62,74-77], which can significantly reduce the freezing risk [64] and permits the application of direct water $[62,74,75,77]$ or indirect water-glycol $[18,37]$ heated vaporizers. However, in the case of marine applications, there are also other common heat sources, such as sea water [18].

The application of water-based heating fluids is associated with freezing risk [64,78]. In the work [78], the authors showed that the risk of total freezing could be indicated by a critical value of Reynolds number and that flattened tubes could improve heat transfer, ensure higher reliability and decrease a pump duty needed to supply a shell-and-tube heat exchanger.

Natural gas has to be heated to temperatures of $0-60{ }^{\circ} \mathrm{C}$ [18] depending on engine requirements [77] and the temperature of the available heat source [75]. The type of vaporizer used also depends on the required natural gas pressure which, in turn, depends on the type of gas engine:

- spark ignition natural gas (SING): typically between 5.2 bar and 8 bar [79? -81];

- port-injected dual-fuel: typically slightly more than 8 bar [79-81];

- high-pressure direct injection (HPDI): at least 208 bar [79,81? -83].

Therefore, LNG vaporizers for mobile applications are typically shell-and-tube heat exchangers (STHX) $[36,62,79,84,85]$, and depending on the fuel injection pressure, they enable either supercritical $[79,82,83]$ or subcritical $[18,62,86]$ regasification. The effect of pressure on the regasification process is shown in Figure 25.

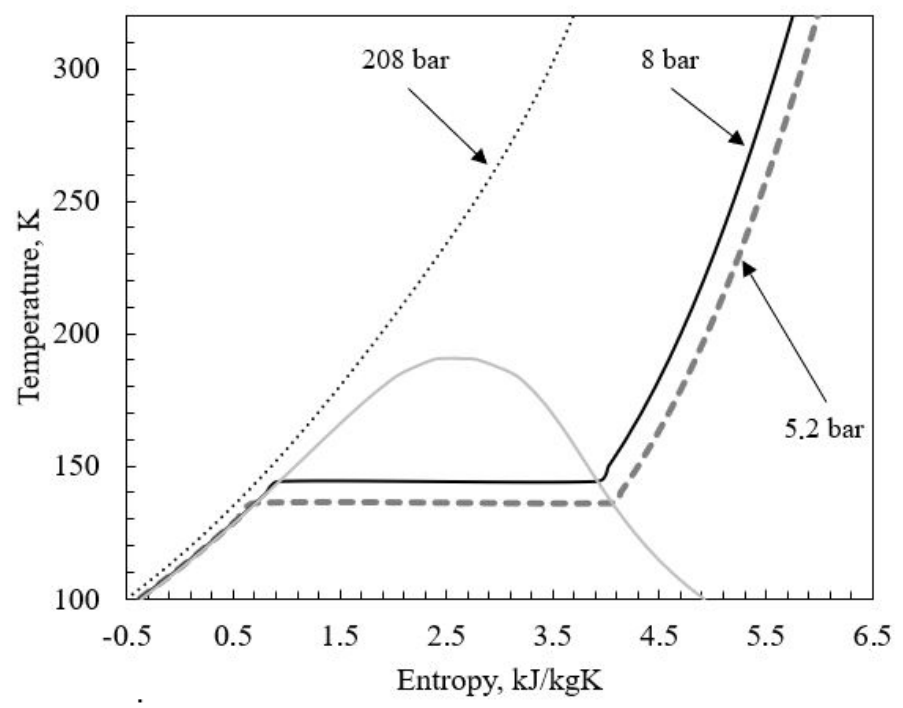

Figure 25. Regasification process of pure methane depending on its pressure for spark ignition natural gas engines (dashed line), port-injected dual-fuel (solid line) and high-pressure direct injection engines (dotted line).

Up to the critical pressure of natural gas, which is approximately 45.992 bar [87], the pressure increase results in a decrease of heat evaporation and an increase of the boiling heat transfer 
coefficient [88-90]. This, in turn, increases the freezing risk [64]. In the case of supercritical pressures, the regasification of LNG proceeds without a phase change, which is also the case in stationary applications [71,91]. Regardless of the engine type, the vaporizer is a STHX which can be located either next to the cryogenic tank $[62,79,80]$ or inside the tank, and integrated with the pump [79] (see Figure 10). In the case of marine applications, vaporizers are rather located next to the tank in the TCS (tank connection space) [18].

\section{Challenges of LNG Regasification}

The design of a water or water-glycol heated vaporizer deals with several challenges:

- risk of freezing of the heating medium [64,71],

- mitigation of LNG maldistribution [84,92-95],

- formation of dead zones at the heating fluid side $[64,84]$, and

- control of LNG boiling heat transfer [64].

In the work of [64], the ice formation effect in a water-heated LNG vaporizer was shown to be mitigated by the precise control of heat transfer effectiveness at the water and LNG sides. Shell-and-tube heat exchangers tend to form dead-zones at the shell side [84], which affects the local heat transfer coefficient and promotes excessive freezing in these regions [64]. Enhanced ice formation can also occur around the tubes due to the significant variation of the local heat transfer coefficient along the circumference $[96,97]$. As shown in [98], these effects can be mitigated by applying helical plates.

The next important challenge related to the optimal performance of vaporizers is associated with flow maldistribution.This phenomenon occurs in HX where the fluid is separated at the inlet and guided in parallel by multiple channels. As a consequence, some sections of the HX are more loaded than others, or some sections are even not fed with the inlet fluid at all. This phenomenon occurs in heat exchangers such as STHX, plate-fin (PFHX) and plate heat exchangers (PHE) and can significantly decrease the heat transfer rate [84,92-95]. Flow maldistribution can be reduced by the proper control of the direction and distribution of the entering fluid. In the case of STHX, this can be achieved by the addition of a flow distributor in the inlet section of the exchanger [84]. The fluid enters the STHX in the form of a jet and strikes the distributor. As a consequence, the jet is stopped and distributed over the entire volume of the exchanger.

A similar approach was utilized in the case of the FPHX $[99,100]$, where the inflow section or the header configuration was modified.The authors of [99] experimentally investigated the flow distribution in PFHX and they proposed new header configurations. The degree of the flow and temperature maldistribution was reported to have been reduced to $16.8 \%$ and $74.8 \%$ by changing the header configuration. In the case of PHE, the flow maldistribution can be even more intense because a typical PHE consists of hundreds of perforated plates forming a network of thin and complex channels [101,102]. Although many studies and experiments have shown their advantage over other heat exchangers [103], the phenomenon of flow maldistribution can be particularly dangerous in the case of evaporators. It can create dead zones in the farthest channels of the PHE, and the vapor may be trapped in certain parts of the device, causing it to dry out locally or to overheat [104-106]. On the other hand, the risk of freezing may be more difficult to estimate compared to other types of exchangers because the flow in topologically complex PHE channels is not obvious $[107,108]$, and some PHE regions may be more susceptible to freezing than others.

In this series of papers [92-95], the authors showed that flow maldistribution could be reduced by adding horizontal dividers to the bottom collector of the PHE. One horizontal divider, as well as several equidistant dividers, was shown to reduce flow maldistribution and improve the overall operation of the PHE.

The last challenge is related to the complexity of the LNG flow boiling process. According to [64], boiling heat transfer is a dominating heat transfer mechanism (it is the smallest). The LNG flow 
boiling coefficient does not only depend on the boiling temperature difference $[88-90,109]$, the surface properties of the tubes [110] and the two phase flow pattern [111], but also on the composition of the LNG [109]. This makes reliable modeling of the LNG flow boiling very complicated, especially taking into account how few experimental studies have been dedicated to this purpose.

\section{Challenges Related to Control Systems in LNG Applications}

LNG could be regarded as a standard liquefied gas fuel containing predominantly methane $\mathrm{CH}_{4}$ and a mixture of ethane $\mathrm{C}_{2} \mathrm{H}_{6}$. However, when compared to LPG (liquefied petroleum gas, containing mostly propane $\mathrm{C}_{3} \mathrm{H}_{8}$ and butane $\mathrm{C}_{4} \mathrm{H}_{10}$ ), LNG remains a significantly more hazardous medium. LNG vapors are highly explosive when mixed with air in a ratio between 5 and $15 \%$. Therefore, very strict safety precautions must be observed when handling and storing LNG. These measures apply both to the structure of the LNG system and the control systems used in such installations. In this chapter, we will try to present some LNG-specific constraints for control systems.

\subsection{General Remarks}

The LNG systems can be divided into a few principal categories, including storage and transport systems (tank systems, bunkering stations) and mobile installations used as fuel supply systems for ships and various types of vehicles. Different classes of LNG systems are subject to different classification regulations. All the components of the particular system and its control software should comply with the relevant standards. A few examples of these regulations are listed below:

- LNG systems for marine applications should be approved by the DNV or an equivalent classification society.

- LNG systems for railroad vehicles or trucks are usually subject to national regulations or international standards (like the Harmonized Technical United Nations Regulations for Wheeled Vehicles described in ECE/TRANS/WP.29/343 [112], which have also been adopted by EU countries as Regulation No 110 Directive [27])

\subsection{Common Requirements for Control Systems for LNG Applications}

All systems that interact directly with the LNG and its vapors should be regarded as circuits located inside the hazardous zone (ATEX Zone 0 according to the ATEX 137 Workplace Directive known also as Directive 99/92/EC [113]), and the proper safety techniques should be implemented:

- all the components inside the hazardous zone should be ATEX-certified (and DNV-certified, or its equivalent, in the case of on-board ship LNG systems);

- other components outside the hazardous zone should be separated by gas-tight walls or equivalent barriers from the explosive zone;

- all the control signals going into or from the ATEX zone should be intrinsically safe. This means that all the electrical signals should use Zener barriers preventing the transfer of unacceptably high energy from the safe area into the hazardous area (see Figure 26);

- all the control devices, measuring instruments and actuators located in the ATEX zone should be properly certified and intrinsically safe;

- all the control system components should be compatible with the ESD (Electrostatic Discharge) safety rules. The proper grounding of all metal parts is essential. The users should adhere to system-specific ESD-safety procedures in order to maintain a safe working environment. 

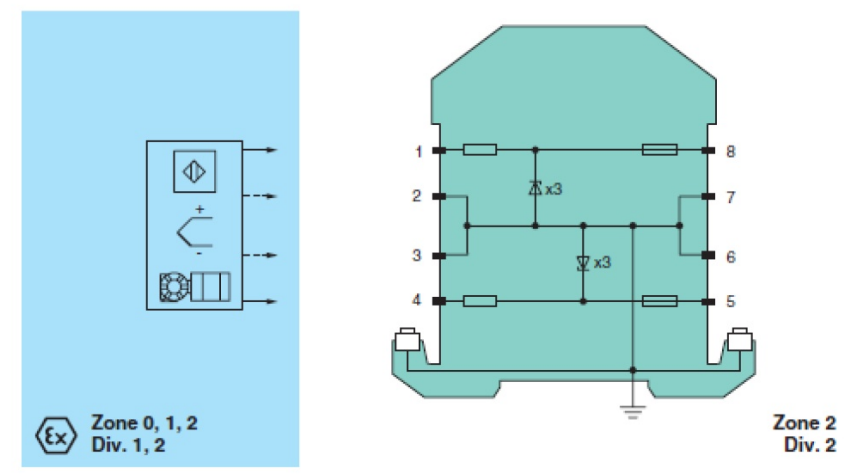

Figure 26. An asymmetrical Zener barrier internal connection (@Pepperl+Fuchs AG).

Zener barriers can usually be used for the processing of electrical signals not exceeding $0.5 \mathrm{~A} / 24 \mathrm{~V}$ DC. In the case of more powerful electrical signals present inside the ATEX zone, two solutions are permissible:

- Selecting a control device that is intrinsically safe on its own (for instance, by having a gas-tight case) and does not require the use of an external Zener barrier.

- Replacement of a high-energy electrical control signal with a pneumatic or hydraulic signal that does not introduce the risk of explosion.

The control system for large LNG installations should usually include redundant control circuits, especially redundant PLC CPUs. The redundancy prevents the lock-up or other malfunction of the control system that might result in a dangerous condition inside the LNG system. If redundant systems are not deployed, special programming techniques may improve the reliability of the software. Classical protection systems like relief valves should, of course, also be implemented. The safety rules for different classes of LNG fuel systems (maritime, railroad and road vehicles) vary slightly due to the separate certification systems for each class of the above-mentioned vehicles. The most demanding safety standards are imposed for ships, with slightly less restrictive standards implemented for locomotives and trucks.

\subsection{LNG—Specific Control Problem}

Among the most common instrumentation problems present in LNG systems is cryogen level measurement inside the storage tank. In the case of large tanks (ship systems), where the tank capacity usually exceeds $10 \mathrm{~m}^{3}$, the LNG level could usually be derived from pressure measurement inside the storage tank. However, for smaller tanks, cryogen level measurement is more difficult. One possible solution is based on a capacitance-based LNG level sensor. The principle of operation for this type of sensor is based on the measurement of capacitance between the set of metallic electrodes located inside the tank. The capacitance of the circuit is increased when the level of the cryogen rises. This change is related to the relative permittivity of LNG (approximately between 1.68 and 1.75). For most practical applications, the $\mathrm{C}_{\mathrm{X}}$ value remains below $10 \mathrm{nF}$. The solution developed by the authors is presented in Figure 27.

Most often, a design with tubular concentric electrodes is used. The main handicap of this configuration is in the relatively low equivalent capacitance between the pair of electrodes. In order to increase this parameter, a multi-electrode design could be implemented. This type of approach makes it possible to increase the equivalent capacitance of the sensor without increasing its size.

The general equation for LNG capacitive sensor signal is

$$
\mathrm{h}_{\mathrm{x}}=\mathrm{C}_{\mathrm{x}} * \mathrm{~K}
$$


where $h_{x}$ is the unknown level of the LNG inside tank, and K is sensitivity factor of the capacitive LNG level sensor expressed by a formula:

$$
\mathrm{K}=\left(\mathrm{h}_{\max }-\mathrm{h}_{\min }\right) /\left(\mathrm{C}_{\max }-\mathrm{C}_{\min }\right)
$$

where $h_{\max }$ and $h_{\min }$ are, respectively, minimal and maximal LNG levels inside the storage tank, and $C_{\max }$ and $C_{\min }$ are capacitances measured between sensor electrodes for minimal and maximal LNG levels.
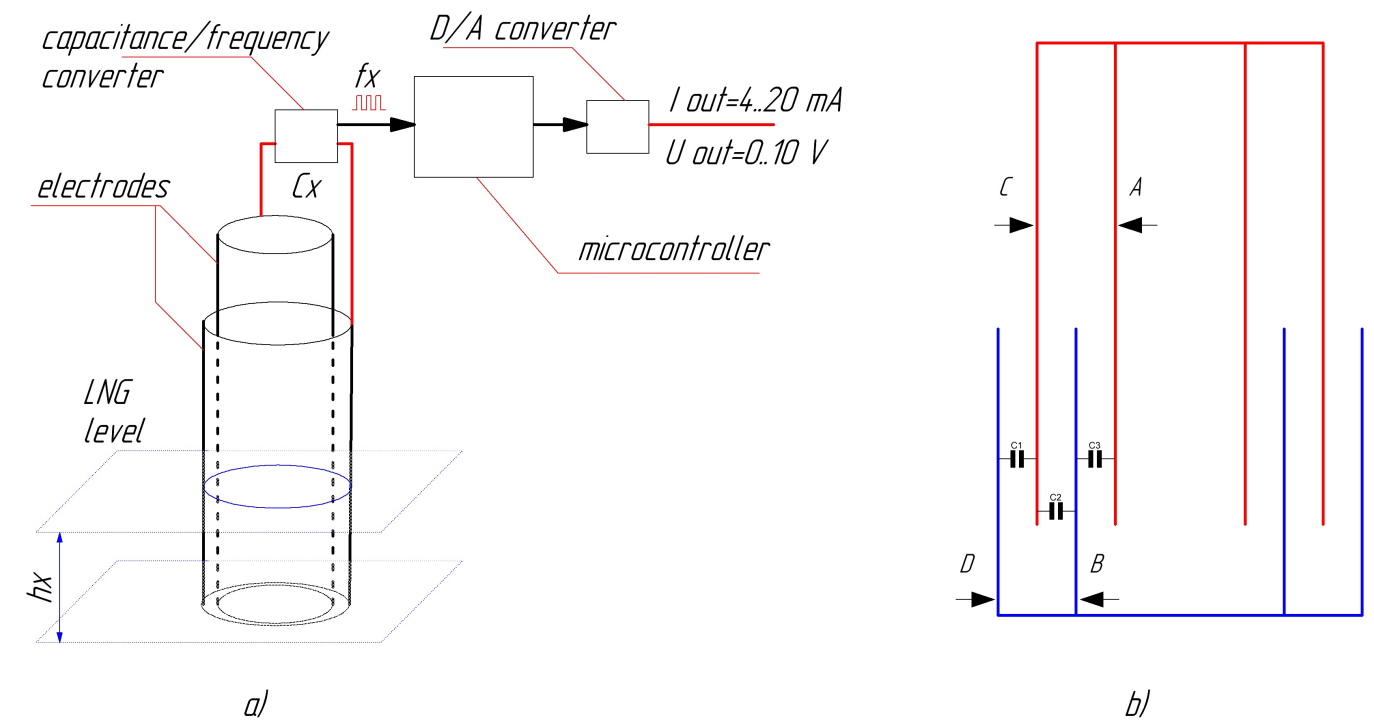

Figure 27. (a) A functional diagram of a capacitive-based LNG sensor with digital data converter and analog output signal; $h_{x}=L N G$ level, $C_{x}=$ capacitance between test electrodes. (b) A cross-section of a multi-electrode sensor with four tubular concentric electrodes A, B, C and D. Solution developed by the authors.

A cross-section of a practical level sensor prototype designed by the authors at Wrocław University of Science and Technology is shown in Figure 28.

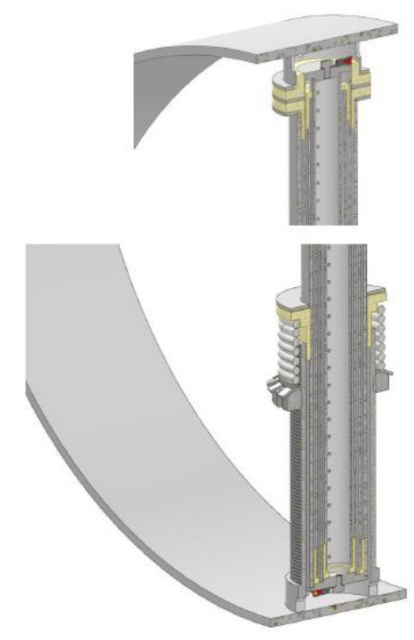

Figure 28. A cross-section view of a multi-electrode LNG level sensor containing 4 tubular electrodes. Yellow-colored parts are PTFE insulating spacers. The design was made by the authors. 
Capacitive sensors are reliable, but the measurement of small internal capacitances present significant challenges in harsh industrial environments. Level sensors for other cryogens, like LHe and $\mathrm{LN}_{2}$, are often constructed with high-temperature superconductors (HTS). However, current HTS materials can only be used in temperatures below $140 \mathrm{~K}$; this condition eliminates the possible applications of a HTS-based sensor inside the LNG storage tank, where the temperature almost always exceeds that level. It is feasible that future HTS materials with higher critical temperature levels will be deployed in LNG systems.

\subsection{Case Study: Fueling Station for Trucks (BISEK-Kostomłoty/CHARTS-Ferox)}

A medium-sized LNG fuel station produced by the CHARTS-Ferox company was commissioned and installed in 2019. The fuel system includes a storage tank $31 \mathrm{~m}^{3}$, pumping systems and an LNG dispenser. The system was located in an empty parking spot in order to minimize the possible safety hazards that would be generated by the uncontrolled release of the LNG (e.g., due to a storage tank rupture). A skid mount greatly simplified the installation of the system (no need to apply for any building regulations and permits). The control system for the station was located in a separate control room (the white container visible behind the storage tank in Figure 29). The station can be used in self-service mode by truck drivers who have passed the necessary internal safety rules training. The driver is able to connect the fuel hose to the truck tank input valve and start the refueling procedure only after the earthing clip is attached. This precaution was introduced in order to avoid the possibility of spark generation by static electricity inside the Ex-Zone.

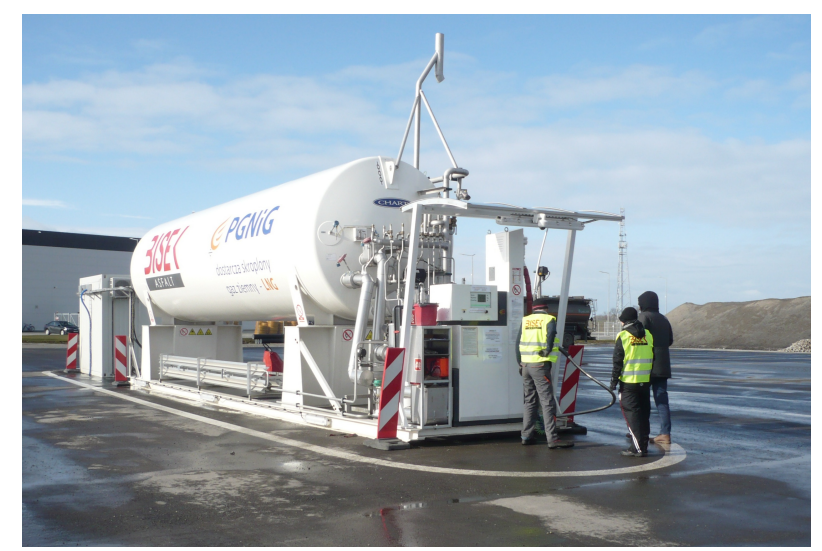

Figure 29. A skid-mounted LNG refueling station including storage tank, transfer pump and LNG dispenser (courtesy of BISEK ASFALT Co., Kostomloty, Poland). The control room is located in a separate container about $5 \mathrm{~m}$ apart from the storage tank and is shown in the background. Storage tank capacity $31 \mathrm{~m}^{3}$

The main storage tank is refilled from the refueler tank truck. In case of an emergency (low LNG fuel level in a detached truck), a small movable micro-refueling station may be used. This system contains a portable $0.96 \mathrm{~m}^{3} \mathrm{LNG}$ storage tank that can be installed on a light car trailer and transported to the desired location. The station is shown in Figure 30. The fuel hose connection, together with the gas nozzle, is presented in Figure 31. 


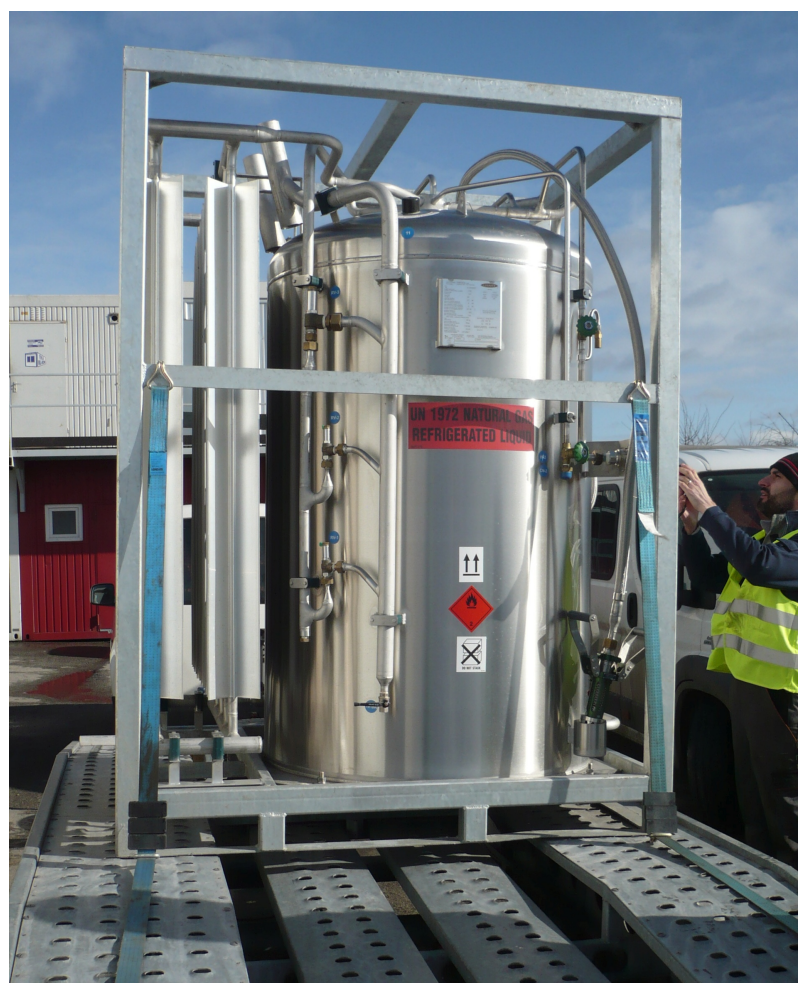

Figure 30. A movable LNG micro-refueling station installed on a car trailer. The system is used for in-field emergency refueling of trucks (courtesy of BISEK ASFALT Co., Kostomloty, Poland). Tank capacity $0.96 \mathrm{~m}^{3}$

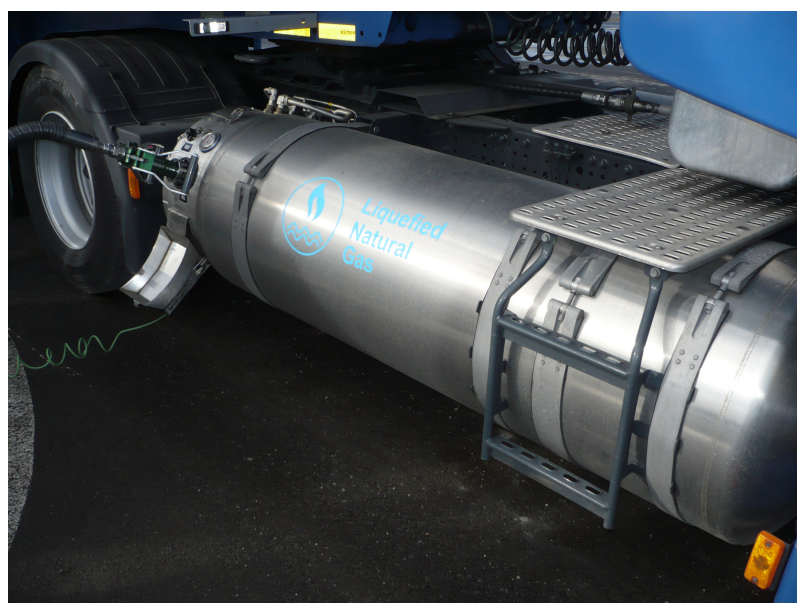

Figure 31. Truck LNG tank during refueling_LNG fuel hose and earthing cable visible (courtesy of BISEK ASFALT Co., Kostomloty, Poland). Tank capacity $0.6 \mathrm{~m}^{3}$

\subsection{Final Remarks}

We may expect that the share of LNG in the commodities and fuel market is very likely to rise significantly over the next few years due to both economic (lower cost) and environmental (reduced combustion gas emission) reasons. However, in order to take advantage of the positive effects of this new fuel, affordable and reliable control systems for LNG should be mass produced and readily available. It should be noted that in the case of a truck-based system control, devices are usually designed and installed by the vehicle producer. However, for large fuel systems like railway diesel-powered locomotives or ships, the systems most likely have to be installed by an independent manufacturer. This type of situation opens an interesting market niche for companies that can convert old systems previously powered solely by diesel fuel into mixed LNG/diesel units. The conversion 
process is additionally stimulated by new environmental regulations defining the acceptable levels for exhaust emissions, like the EU's Euro VI standard for trucks and buses [114].

\section{Conclusions}

LNG is the most popular intermediate maritime fuel now in use. The technology is well developed, and the number of ships fueled with this cryogen is of about 200 now with the same number under construction. In land transport, LNG is a promising fuel for trucks and locomotives. The main issues are safe and reliable construction of LNG fueling systems, bunkering infrastructure and procedures as well recondensation and exergy recovery, when economically justified.

Technically, most of the problems have been solved for mobile applications; however, the LNG mobile system thermodynamic and economic optimization is still a challenge, with respect to thermodynamic efficiency and holding time. Novel concepts of LNG physical exergy recovery, based on thermoelectric generators (TEG) and absorbed natural gas (ANG) technologies, have been proposed and experimentally tested. The technologies can be economically justified in waterborne transportation; TEG may be also considered in land transport contributing positively to energy balance of a truck or locomotive. The LNG recondensation is a predominant issue in marine transportation. A four-stage cascade refrigerator has been proposed on the basis of available technologies assessedt.

Thanks to new fueling technologies, LNG has been successfully introduced in mobile applications triggering a fast development of low-emission ships and vehicles. LNG, being still an intermediate fuel, has introduced technologies allowing further transition of transportation towards zero-emissivity. Cryogenic technologies like vacuum-insulated LNG tanks, two-phase heat exchangers, exergy recovery and recondensation systems are a good step in the direction of hydrogen economy. The competences gained with the development of LNG components will facilitate the spread of future hydrogen cryogenic systems. LNG is a fuel than can supply fuel cells, especially solid oxide fuel cells (SOFC). It may play a important role in retrofitting the existing ships to zero-emissivity requirements. It may also encourage a fast development of "green LNG" - a mixture of LNG with a purified and liquefied biogas.

Another option replacing LNG and using the experiences coming from the LNG regulations is ammonia- a perspective fuel that may be based of renewable energy sources. Ammonia can be directly converted to electricity in SOFC systems. A number of studies have shown that the conversion efficiency can approach $80 \%$ [115-117].

Author Contributions: Conceptualization, T.B., M.C., W.G., A.J., J.K., Z.M., A.P., J.P., Z.R., K.S., J.S., M.S., K.T. and P.D.; methodology, T.B., M.C., W.G., A.J., J.K., A.P., J.P., K.S., J.S., M.S. and K.T.; formal analysis, T.B., M.C., W.G., A.J., J.K., Z.M., A.P., J.P., Z.R., K.S., J.S. and M.S.; investigation, T.B., W.G., A.J., J.K., A.P., K.S. and K.T.; writing-original draft preparation, T.B., M.C., W.G., A.J., J.K., Z.M., A.P., J.P., Z.R., K.S., J.S. and M.S.; writing-review and editing, Z.M. and M.S.; supervision, M.C. and Z.M.; funding acquisition, M.C. All authors have read and agreed to the published version of the manuscript.

Funding: This research was funded by National Center for Research and Development of Poland under grant No. POIR.01.01.01-00-0842/16-00, 2016-2022.

Acknowledgments: The authors would like to thank Chia-Luen Lee for her careful proofreading and language corrections.

Conflicts of Interest: The authors declare no conflict of interest.

\section{References}

1. Wróblewski, Z.C.O. Ueber dieVerflüssigung des Sauerstoffs, Stickstoffs und Kohlenoxyds. Wiedemann's Ann. Phys. 1883, 20, 243. [CrossRef]

2. Olszewski, C. XIX. On the liquefaction of gases. Lond. Edinb. Dublin Philos. Mag. J. Sci. 2009, 39, 188-212. [CrossRef]

3. Rogers, G.S. Helium-Bearing Natural Gas; Professional Paper 121; Department of the Interior, Governement Printing Office: Washington, DC, USA, 1921; pp. 6-8. 
4. David, D.; Van Tassel, J.J.; Grabowski, C.B.C. East Ohio Gas Co. Explosion and Fire. In The Encyclopedia of Cleveland History; Indiana University Press: Bloomington, IN, USA, 1996.

5. Silvermann, A. Gas Fire's Tidal Wave Leaves $\$ 5.000 .000$ Ruin in 55th-St. Clair Area. In Cleveland Plain Dealer; Advance Publications, Inc.: Cleveland, OH, USA, 1944.

6. Elliott, M.A. Report on the Investigation of the Fire at the Liquefaction Storage, and the Regasification Plant of the East Ohio Co., Cleveland Ohio, 20 October 1944; Bureau of Mines: Washington, DC, USA, 1946.

7. DNV-GL (Ed.) Status and Trends for Uptake of Alternative Fuels; DNV-GL Alternative Fuels Online Conference, Oslo, Norway, 25 September 2019.

8. Paltsev, S. Scenarios for Russia's Natural Gas Exports to 2050. Energy Econ. 2014, 42, 262-270, [CrossRef]

9. US Energy Information Administration. 2020. Available online: https://www.eia.gov/ (accessed on 10 July 2020).

10. Shell. LNG Outlook 2020. Available online: https://www.shell.com/energy-and-innovation/natural-gas / liquefied-natural-gas-lng/lng-outlook-2020.html/ (accessed on 10 July 2020).

11. Hao, H.; Liu, Z.; Zhao, F.; Li, W. Natural gas as vehicle fuel in China: A review. Renew. Sustain. Energy Rev. 2016, 62, 521-533. [CrossRef]

12. NGVA. 2020. Available online: https:/ / www.ngva.eu/ (accessed on 10 July 2020).

13. The Oxford Institute for Energy Studies. A Review of Prospects for Natural Gas as a Fuel in Road Transport. Available online: https://www.oxfordenergy.org/publications/review-prospects-natural-gas-fuel-roadtransport / / (accessed on 10 July 2020).

14. Lee, I.; Park, J.; Moon, I. Key Issues and Challenges on the Liquefied Natural Gas Value Chain: A Review from the Process Systems Engineering Point of View. Ind. Eng. Chem. Res. 2018, 57, 5805-5818. [CrossRef]

15. Kanbur, B.; Xiang, L.; Choo, F.; Duan, F. Cold utilization systems of LNG: A review. Renew. Sustain. Energy Rev. 2017, 79, 1171-1188. [CrossRef]

16. Park, J.; Lee, I.; You, F.; Moon, I. Economic Process Selection of Liquefied Natural Gas Regasification: Power Generation and Energy Storage Applications. Ind. Eng. Chem. Res. 2019, 58, 4946-4956. [CrossRef]

17. DNV GL Maritime Communications. In Focus - LNG as ship fuel. 2015.

18. Chorowski, M.; Duda, P.; Polinski, J.; Skrzypacz, J. LNG systems for natural gas propelled ships. IOP Conf. Ser. Mater. Sci. Eng. 2015, 101, 012089. [CrossRef]

19. IGC Code. International Code for the Construction and Equipment of Ships Carrying Liquefied Gases in Bulk; IMO Publishing: London, UK, 2016.

20. IGF Code. International Code of Safety for Ships Using Gases or Other Low-Flashpoint Fuels; IMO Publishing: London, UK, 2016.

21. DNV Classification Notes No. 31.13. Strength Analysis of Independent Type C Tanks; DNVGL: Oslo, Norway, 2013.

22. DNV GL. Rules for Classification. Ships. Part 5-Ships Types; Chapter 7-Liquefied gas tankers; DNVGL: Oslo, Norway, 2017.

23. Skrzypacz, J.; Jaszak, P. Selected Aspects of Cryogenic Tank Fatigue Calculations for Offshore Application. Int. J. Appl. Mech. Eng. 2018, 23, 251-259. [CrossRef]

24. Fesmire, J.E.; Augustynowicz, A.D.; Rouanet, S. Aerogel beads as cryogenic thermal insulation system. In AIP Conference Proceedings; AIP: College Park, MD, USA, 2002 ; Volume 613, [CrossRef]

25. Wartisla. Creating Optimal LNG Storage Solutions. 2015. Available online: www.wartsila.com (accessed on 10 July 2020).

26. Lisowski, E.; Czyżycki, W.; Łazarczyk, K. Using of polyamide in construction of supporting blocks of cryogenic tanks on example of LNG container. Arch. Foundry Eng. 2010, 10, 81-86.

27. Commission, E. Regulation No 110 of the Economic Commission for Europe of the United Nations (UNECE) - Uniform Provisions Concerning the Approval of Vehicles with Regard to the Installation of Specific Components of an Approved Type for the Use of Compressed Natural Gas (CNG) and/or Liquefied Natural Gas (LNG) in Their Propulsion System [2015/999]. 2015. Available online: https: / / eur-lex.europa.eu/legal-content/EN/TXT/?uri=CELE (accessed on 10 July 2020).

28. SAG. 2020. Available online: https://www.sag.at/en/ (accessed on 10 July 2020).

29. Fire, I.A.; Services, R. 2018. Available online: https:/ / www.ctif.org (accessed on 10 July 2020).

30. Harper, G.; Powars, C. Advanced LNG Onboard Storage System; Technical report; Cummins Westport Inc.: Vancouver, BC, USA, 2003.

31. Cleveland, C.J. Energy Dictionary; Expanded ed.; Morris, C., Ed.; Elsevier: Amsterdam, The Netherlands, 2009. 
32. Roszak, E.A.; Chorowski, M. Exergy of LNG regasification-Possible utilization method. Case study of LNG-ANG coupling. In AIP Conference Proceedings; AIP: College Park, MD, USA, 2014; Volume 1573, doi:10.1063/1.4860867. [CrossRef]

33. Liu, H.; You, L. Characteristics and applications of the cold heat exergy of liquefied natural gas. Energy Convers. Manag. 1999, 40, 1515-1525. [CrossRef]

34. Dorosz, P.; Wojcieszak, P.; Malecha, Z. Exergetic Analysis, Optimization and Comparison of LNG Cold Exergy Recovery Systems for Transportation. Entropy 2018, 20, 59. [CrossRef]

35. Liquefied Natural Gas for Trucks and Buses; SAE Technical Papers: Warrendale, PA, USA, 2000. [CrossRef]

36. Powars, C.A.; Derbidge, T.C. Liquefaction Energy Recovery in LNG and LH2 Fueled Vehicles; Technical Report 724; SAE Technical Papers: Warrendale, PA, USA, 2000. [CrossRef]

37. Boulougouris, E.K.; Chrysinas, L.E. LNG Fueled Vessels Design Training. 2015. Available online: https: / / www.onthemosway.eu/wp-content/uploads/2015/06/Lecture-Notes.pdf (accessed on 10 July 2020).

38. Rocca, V.L. Cold recovery during regasification of LNG part one: Cold utilization far from the regasification facility. Energy 2010, 35, 2049-2058. [CrossRef]

39. Sung, T.; Kim, K.C., LNG Cold Energy Utilization Technology. In Energy Solutions to Combat Global Warming; Springer International Publishing: Berlin/Heidelberg, Germany, 2017; pp. 47-66. [CrossRef]

40. Chang, J.; Zuo, J.; Lu, K.J.; Chung, T.S. Freeze desalination of seawater using LNG cold energy. Water Res. 2016, 102, 282-293. [CrossRef]

41. Tsatsaronis, G.; Morosuk, T. Advanced exergetic analysis of a novel system for generating electricity and vaporizing liquefied natural gas. Energy 2010, 35, 820-829. [CrossRef]

42. Gizicki, W.; Banaszkiewicz, T.; Wojcieszak, P.; Rogala, Z. Performance analysis of small-scale power cycles for LNG physical exergy recovery. IOP Conf. Ser. Mater. Sci. Eng. 2019, 502, 012146. [CrossRef]

43. Gómez, M.R.; Garcia, R.F.; Gómez, J.R.; Carril, J.C. Review of thermal cycles exploiting the exergy of liquefied natural gas in the regasification process. Renew. Sustain. Energy Rev. 2014, 38, 781-795. [CrossRef]

44. Szargut, J.; Szczygiel, I. Utilization of the cryogenic exergy of liquid natural gas (LNG) for the production of electricity. Energy 2009, 34, 827-837. [CrossRef]

45. Choi, I.H.; Lee, S.; Seo, Y.; Chang, D. Analysis and optimization of cascade Rankine cycle for liquefied natural gas cold energy recovery. Energy 2013, 61, 179-195. [CrossRef]

46. Bisio, G.; Tagliafico, L. On the recovery of LNG physical exergy by means of a simple cycle or a complex system. Exergy Int. J. 2002, 2, 34-50. doi:10.1016/S1164-0235(01)00037-1. [CrossRef]

47. Riffat, S.; Ma, X. Thermoelectrics: A review of present and potential applications. Appl. Therm. Eng. 2003, 23, 913-935. doi:10.1016/S1359-4311(03)00012-7. [CrossRef]

48. Sun, W.; Hu, P.; Chen, Z.; Jia, L. Performance of cryogenic thermoelectric generators in LNG cold energy utilization. Energy Convers. Manag. 2005, 46, 789-796. [CrossRef]

49. Champier, D. Thermoelectric generators: A review of applications. Energy Convers. Manag. 2017, 140, $167-181$. [CrossRef]

50. ISO 12991:2012(en), Liquefied natural gas (LNG)-Tanks for on-board storage as a fuel for automotive vehicles. In Standard, International Organization for Standardization; British Standards Institution: London, UK, 2012.

51. Karabetoglu, S.; Sisman, A.; Ozturk, Z.F.; Sahin, T. Characterization of a thermoelectric generator at low temperatures. Energy Convers. Manag. 2012, 62, 47-50. [CrossRef]

52. Roszak, E.; Chorowski, M. Exergy analysis of combined simultaneous Liquid Natural Gas vaporization and Adsorbed Natural Gas cooling. Fuel 2013, 111, 755-762. [CrossRef]

53. Strobridge, T. Cryogenic Refrigerators-An Updated Survey; National Bureau of Standards: Washington, DC, USA, 1974.

54. Gomez, J.R.; Gomez, M.R.; Garcia, R.F.; Catoira, A.D.M. On board LNG reliquefaction technology: A comparative study. Pol. Marit. Res. 2014, 21,77-88. [CrossRef]

55. BOG Handling Method for Energy Saving in LNG Receiving Terminal. In 21st European Symposium on Computer Aided Process Engineering; Pistikopoulos, E., Georgiadis, M., Kokossis, A., Eds.; Computer Aided Chemical Engineering; Elsevier: Amsterdam, The Netherlands, 2011; Volume 29, pp. 1829-1833. doi:10.1016/B978-0-444-54298-4.50144-6. [CrossRef]

56. Kochunni, S.K.; Chowdhury, K. LNG boil-off gas reliquefaction by Brayton refrigeration system-Part 1: Exergy analysis and design of the basic configuration. Energy 2019, 176, 753-764. [CrossRef] 
57. Xu, Y.; Sun, D.; Qiao, X.; Yu, Y.S.; Zhang, N.; Zhang, J.; Cai, Y. Operating characteristics of a single-stage Stirling cryocooler capable of providing $700 \mathrm{~W}$ cooling power at $77 \mathrm{~K}$. Cryogenics 2017, 83, 78-84. [CrossRef]

58. Hu, J.; Zhu, J.; Chen, S.; Luo, E.; Dai, W.; Li, H. An Efficient Pulse Tube Cryocooler for BOG Recondensation in LNG Tanks. Energy Procedia 2014, 61, 2678-2681. [CrossRef]

59. Dang, H.; Li, J.; Zha, R.; Tan, J.; Zhang, T.; Zhao, B.; Zhao, Y.; Li, N.; Tan, H.; Xue, R. A single-stage Stirling-type pulse tube cryocooler achieving $1080 \mathrm{~W}$ at $77 \mathrm{~K}$ with four cold fingers driven by one linear compressor. Cryogenics 2020, 106, 103045. [CrossRef]

60. Dorosz, P.; Chorowski, M.; Piotrowska, A. Performance of the one-stage Joule-Thomson cryocooler fed with a nitrogen-hydrocarbon mixture and built from mass-produced components made for the refrigeration industry. Int. J. Refrig. 2017, 82, 252-261. [CrossRef]

61. Gómez, J.R.; Gómez, M.R.; Bernal, J.L.; Insua, A.B. Analysis and efficiency enhancement of a boil-off gas reliquefaction system with cascade cycle on board LNG carriers. Energy Convers. Manag. 2015, 94, $261-274$. [CrossRef]

62. Chart LNG. Vehicle Fuel Tank System. Available online: http:// files.chartindustries.com/3835849-LNGOperations-Manual-Final-Draft-010515-web.pdf (accessed on 10 July 2020).

63. Wang, Z.; Cai, W.; Han, F.; Ji, Y.; Li, W.; Sundén, B. Feasibility study on a novel heat exchanger network for cryogenic liquid regasification with cooling capacity recovery: Theoretical and experimental assessments. Energy 2019, 181, 771-781. [CrossRef]

64. Rogala, Z.; Brenk, A.; Malecha, Z. Theoretical and Numerical Analysis of Freezing Risk During LNG Evaporation Process. Energies 2019, 12, 1426. [CrossRef]

65. Hisada, N.; Sekiguchi, M. Design and Analysis of Open Rack LNG Vaporizer; ASME: New York, NY, USA, 2004. [CrossRef]

66. Qi, C.; Wang, W.; Wang, B.; Kuang, Y.; Xu, J. Performance analysis of submerged combustion vaporizer. J. Nat. Gas Sci. Eng. 2016, 31, 313-319. [CrossRef]

67. Jin, T.; Wang, M.; Tang, K. Simulation and performance analysis of a heat transfer tube in SuperORV. Cryogenics 2014, 61, 127-132. [CrossRef]

68. Bai, J.; Pan, J.; Wang, W.; Wang, K.; Wu, G. Ice formation prediction and heat transfer analysis of LNG in serpentine tube under supercritical pressure. Int. J. Therm. Sci. 2020, 149, 106137. [CrossRef]

69. Han, C.1.; Ren, J.J.; Wang, Y.Q.; Dong, W.P.; Bi, M.S. Experimental investigation on fluid flow and heat transfer characteristics of a submerged combustion vaporizer. Appl. Therm. Eng. 2017, 113, 529-536. [CrossRef]

70. Xu, S.; Chen, X.; Fan, Z. Thermal design of intermediate fluid vaporizer for subcritical liquefied natural gas. J. Nat. Gas Sci. Eng. 2016, 32, 10-19. [CrossRef]

71. Zhao, Z.; Zhou, Y.; Ma, X.; Chen, X.; Li, S.; Yang, S. Numerical Study on Thermal Hydraulic Performance. Energies 2019, 12, 548, [CrossRef]

72. Gis, W.; Żółtawski, A.; Taubert, S.; Grzelak, P. Engine Testing of Bus Fuelled With LNG. J. KONES 2015, 20, 93-98. [CrossRef]

73. Barta, D.; Brezani, M.; Kalina, T. LNG as Alternative Fuel For Railway Transport. Bezpieczestwo i Ekologia 2017, 6, 47-49.

74. Wärtsilä. Wärtsilä LNGPac; Technical report. 2017. Available online: http://wpci.nl/lng/sites/default/ files / 2010\%20Wartsila\%20safe-storage-gas-lngpac.pdf (accessed on 10 July 2020).

75. MAN Cryo. Marine LNG Fuel Gas Systems. Available online: https://sweden.mandieselturbo.com/ docs/librariesprovider16/cryo-files/man-cryo-marine-lng-fuel-gas-systems.pdf?sfvrsn=0 (accessed on 10 July 2020).

76. Karlsson, S.; Sonzio, L. Enabling the safe storage of gas onboard ships with the Wärtsilä LNGPac. WÄRTSILÄ Tech. J. 2010, 52-56. Available online: http://wpci.nl/lng/sites/default/files/2010\% 20Wartsila\%20safe-storage-gas-lngpac.pdf (accessed on 10 July 2020).

77. Buades, L.S. Implementation of LNG as Marine Fuel in Current Vessels. Perspectives and Improvements on Their Environmental Efficiency. Llorenç Sastre Buades. Ph.D. Thesis, Univesitat Politecnica de Catalunya, Barcelona, Spain, 2017.

78. Brenk, A.; Kielar, J.; Malecha, Z.; Rogala, Z. The effect of geometrical modifications to a shell and tube heat exchanger on performance and freezing risk during LNG regasification. Int. J. Heat Mass Transf. 2020, 161, 120247. [CrossRef] 
79. United States Department of Energy (DOE); Cummins Westport Inc. Advanced LNG Onboard Storage System (ALOSS); Technical report; Cummins Westport Inc.: Vancouver, BC, Canada, 2003.

80. LNG vehicle fuel pressure strategy alternatives. SAE Tech. Pap. 2001, 110, 1098-1112. [CrossRef]

81. International Maritime Organisation. Safe, secure and efficient shipping on clean oceans studies on the feasibility and use of $\operatorname{lng}$ as a fuel for shipping. In Air Pollution and Energy Efficiency Studies 3; IMO: London, UK, 2016.

82. Cox, G.; DelVecchio, K.; Hays, W.; Hiltner, J.; Nagaraj, R.; Emmer, C. Development of a Direct-Injected Natural Gas Engine System for Heavy-Duty Vehicles: Final Report Phase 2; Technical Report February; National Renewable Energy Lab.: Golden, CO, USA, 2000. [CrossRef]

83. Souto, J.L.P.; Ferrera, M.; Leclerq, N.; Matchett, M.; Ingemar, M. LNG Trucks Euro V Technical Solutions. Available online: https://lngbc.eu/system/files/deliverable_attachments/LNG\%20BC\%20D\%202.1\% 20Euro\%20V\%20final\%20technical\%20solutions.pdf (accessed on 10 July 2020).

84. DongHwa Entec. Available online: http://www.dh.co.kr/fuel-gas-supply-system/ (accessed on 10 July 2020).

85. Prasad, G.; Das, A. Design approach of shell and Tube Vaporizer for LNG regasification. Jordan J. Mech. Ind. Eng. 2018, 12, 109-116.

86. Agility Fuel Solutions. Dual Tank LNG System Operation Manual; Technical Report July; Costa Mesa, CA, USA, 2017.

87. Lemmon, E.W.; Bell, I.H.; Huber, M.L.; McLinden, M.O. NIST Standard Reference Database 23: Reference Fluid Thermodynamic and Transport Properties-REFPROP, Version 10.0, National Institute of Standards and Technology; NIST: Gaithersburg, MD, SUA, 2018. doi:10.18434/T4JS3C. [CrossRef]

88. Bier, K.; Lambert, M. Heat transfer in nucleate boiling of different low boiling substances. Int. J. Refrig. 1990, 13, 293-300. [CrossRef]

89. Ackermann, H.; Bewilogua, L.; Jahn, A.; Kn, R.; Vinzelberg, H. Heat transfer in nitrogen-methane mixtures under pressure with film boiling. Cryogenics 1976, 16, 497-499. [CrossRef]

90. Sciance, C.T.; Colver, C.P.; Sliepcevich, C.M. Pool Boiling of Methane between Atmospheric Pressure and the Critical Pressure. In Advances in Cryogenic Engineering; Springer: Boston, MA, USA, 1967; pp. 395-408. [CrossRef]

91. Xu, S.; Chen, X.; Fan, Z.; Chen, Y.; Nie, D.; Wu, Q. The influence of chemical composition of LNG on the supercritical heat transfer in an intermediate fluid vaporizer Cryogenics 2018, 91, 47-57. [CrossRef]

92. Malecha, Z.; Płuszka, P.; Brenk, A. Numerical investigation of cryogen re-gasification in a plate heat exchanger. In IOP Conference Series: Materials Science and Engineering; IOP Publishing: Bristol, UK, 2017; Volume 278, p. 012063.

93. Brenk, A.; Pluszka, P.; Malecha, Z. Numerical study of flow maldistribution in multi-plate heat exchangers based on robust 2D model. Energies 2018, 11, 3121. [CrossRef]

94. Liao, W.K.; Malecha, Z.; Płuszka, P.; Brenk, A.; Lin, F.C.; Yang, C.Y. An experimental and numerical analysis of air-water flow distribution in multichannels with parallel dividing plates in the inlet header. In Proceedings of the 29th International Symposium on Transport Phenomena (ISTP29), Honolulu, HI, USA, 30 October-2 November 2018.

95. Pluszka, P.; Brenk, A.P.; Malecha, Z. Numerical study of flow maldistribution in plate heat exchangers used for evaporation process. Arch. Thermodyn. 2019, 40, 57-82. [CrossRef]

96. Aiba, S.; Ota, T.; Tsuchida, H. Heat Transfer and Flow Around a Circular Cylinder with Tripping-Wires. Thermo- Fluid Dyn. 1979, 12, 221-231. [CrossRef]

97. Cengel, Y.a.; Klein, S.; Beckman, W. Heat Transfer: A Practical Approach; Mcgraw-Hill: New York, NY, USA, 2002; p. 896.

98. Gugulothu, R.; Sanke, N.; Gupta, A.V. Numerical Study of Heat Transfer Characteristics in Shell-and-Tube Heat Exchanger; Number March; Springer: Singapore, 2019; pp. 375-383. [CrossRef]

99. Zhang, Z.; Mehendale, S.; Tian, J.; Li, Y. Fluid Flow Distribution and Heat Transfer in Plate-Fin Heat Exchangers. Heat Transf. Eng. 2015, 36, 806-819. [CrossRef]

100. Cao, X.; Liu, H.L.; Shao, X.D. Heat Transfer Performance of a Novel Multi-Baffle-Type Heat Sink. Entropy 2018, 20, 979. [CrossRef]

101. Mueller, A.C.; Chiou, J.P. Review of various Types of Flow Maldistribution in Heat Exchangers. Heat Transf. Eng. 1988, 9, 36-50. [CrossRef] 
102. Pacio, J.C.; Dorao, C.A. A study of the effect of flow maldistribution on heat transfer performance in evaporators. Nucl. Eng. Des. 2010, 240, 3868-3877. [CrossRef]

103. Yan, Y.Y.; Lin, T.F. Evaporation Heat Transfer and Pressure Drop of Refrigerant R-134a in a Plate Heat Exchanger. J. Heat Transf. 1999, 121, 118-127. [CrossRef]

104. Vist, S.; Pettersen, J. Two-phase flow distribution in compact heat exchanger manifolds. Exp. Therm. Fluid Sci. 2004, 28, 209-215. [CrossRef]

105. Sterner, D.; Sunden, B. Performance of Plate Heat Exchangers for Evaporation of Ammonia. Heat Transf. Eng. 2006, 27, 45-55. [CrossRef]

106. Jensen, J.K.; Kaernl, M.R.; Ommen, T.S.; Brix, W.; Reinholdt, L.; Elmeegard, B. Effect of liquid/vapour maldistribution on the performance of plate heat exchanger evaporators. In Proceedings of the 24th IIR International Congress of Refrigeration, Yokohama, Japan, 16-22 August 2015.

107. Yang, C.Y.; Lin, Y.H.; Lin, F.C. Effect of Flow Direction for the Heat Transfer Performance of Refrigerant R-410A Evaporation in a Plate Heat Exchanger. Heat Transf. Eng. 2013, 34, 1133-1139. [CrossRef]

108. Lin, Y.H.; Li, G.C.; Yang, C.Y. An experimental observation of the effect of flow direction for evaporation heat transfer in plate heat exchanger. Appl. Therm. Eng. 2015, 88, 425-432; doi:10.1016/j.applthermaleng.2014.11.074. [CrossRef]

109. Gong, M.; Ma, J.; Wu, J.; Zhang, Y.; Sun, Z.; Zhou, Y. Nucleate pool boiling of liquid methane and its natural gas mixtures. Int. J. Heat Mass Transf. 2009, 52, 2733-2739. [CrossRef]

110. Jones, B.J.; McHale, J.P.; Garimella, S. The Influence of Surface Roughness on Nucleate Pool Boiling Heat Transfer. J. Heat Transf. 2009, 131, 12009. [CrossRef]

111. Beggs, H.D.; Brill, J.P. A Study of Two-Phase Flow in Inclined Pipes. J. Pet. Tehchnol. 1973, 25, 607-617. [CrossRef]

112. Nations, U. United Nations Economic and Social Council-Agreement Concerning the Adoption of Harmonized Technical United Nations Regulations for Wheeled Vehicles, Equipment and Parts which Can Be Fitted and/or be Used on Wheeled Vehicles and the Conditions for Reciprocal Recognition of Approvals Granted on the Basis of these United Nations Regulations. 2020. Available online: http: / /www.unece.org/trans/main/wp29/wp29wgs/wp29gen/wp29fdocstts.html (accessed on 10 July 2020).

113. EU Commission Directive 1999/92/EC of the European Parliament and of the Council of 16 December 1999 on Minimum Requirements for Improving the Safety and Health Protection of Workers Potentially at Risk from Explosive Atmospheres (15th Individual Directive within the Meaning of Article 16(1) of Directive 89/391/EEC). 1999. Available online: https:/ / eur-lex.europa.eu/legal-content/EN/TXT/?uri=CELEX\% 3A31999L0092 (accessed on 10 July 2020).

114. Commission Regulation (EU) No 582/2011 of 25 May 2011 implementing and amending Regulation (EC) No 595/2009 of the European Parliament and of the Council with Respect to Emissions from Heavy Duty Vehicles (Euro VI) and Amending ANNEXES I and III to Directive 2007/46/EC of the European Parliament and of the Council Text with EEA Relevance. 2011. Available online: https://eur-lex.europa.eu/legalcontent/EN/TXT/?uri=CELEX:32011R0582 (accessed on 10 July 2020).

115. Kupecki, J.; Jewulski, J.; Motylinski, K. Parametric evaluation of a micro-CHP unit with solid oxide fuel cells integrated with oxygen transport membranes. Int. J. Hydrog. Energy 2015, 40, 11633-11640. [CrossRef]

116. Kupecki, J.; Papurello, D.; Lanzini, A.; Naumovich, Y.; Motylinski, K.; Blesznowski, M.; Santarelli, M. Numerical model of planar anode supported solid oxide fuel cell fed with fuel containing H2S operated in direct internal reforming mode (DIR-SOFC). Appl. Energy 2018, 230, 1573-1584. [CrossRef]

117. Kupecki, J.; Motylinski, K.; Jagielski, S.; Wierzbicki, M.; Brouwer, J.; Naumovich, Y.; Skrzypkiewicz, M. Energy analysis of a $10 \mathrm{~kW}$-class power-to-gas system based on a solid oxide electrolyzer (SOE). Energy Convers. Manag. 2019, 199, 111934. doi:10.1016/j.enconman.2019.111934. [CrossRef]

Publisher's Note: MDPI stays neutral with regard to jurisdictional claims in published maps and institutional affiliations. 